\title{
Article \\ Genetic Dissection of Phosphorus Use Efficiency in a Maize Association Population under Two P Levels in the Field
}

\author{
Dongdong Li ${ }^{1,+}$, Haoying Wang ${ }^{1,+}$, Meng Wang ${ }^{1,+}$, Guoliang Li $^{1}$, Zhe Chen ${ }^{2}$, Willmar L. Leiser ${ }^{3} \mathbb{D}$, \\ Thea Mi Weiß ${ }^{3,4} \mathbb{D}$, Xiaohuan Lu ${ }^{1,5}$, Ming Wang ${ }^{1}$, Shaojiang Chen ${ }^{1}$, Fanjun Chen ${ }^{2}$, Lixing Yuan ${ }^{2} \mathbb{D}$, \\ Tobias Würschum ${ }^{4}\left(\mathbb{D}\right.$ and Wenxin Liu ${ }^{1, * \mathbb{D}}$
}

Citation: Li, D.; Wang, H.; Wang, M.; Li, G.; Chen, Z.; Leiser, W.L.; Weiß,

T.M.; Lu, X.; Wang, M.; Chen, S.; et al. Genetic Dissection of Phosphorus Use Efficiency in a Maize Association Population under Two P Levels in the Field. Int. J. Mol. Sci. 2021, 22, 9311. https://doi.org/10.3390/ijms22179311

Academic Editor: Ryoung Shin

Received: 9 July 2021

Accepted: 25 August 2021

Published: 27 August 2021

Publisher's Note: MDPI stays neutral with regard to jurisdictional claims in published maps and institutional affiliations.

Copyright: (c) 2021 by the authors Licensee MDPI, Basel, Switzerland. This article is an open access article distributed under the terms and conditions of the Creative Commons Attribution (CC BY) license (https:/ / creativecommons.org/licenses/by/ $4.0 /)$.
1 Key Laboratory of Crop Heterosis and Utilization, the Ministry of Education, Key Laboratory of Crop Genetic Improvement, Beijing Municipality, National Maize Improvement Center, College of Agronomy and Biotechnology, China Agricultural University, Beijing 100193, China; dongdongli@cau.edu.cn (D.L.); wanghaoying98@163.com (H.W.); wm1212131@163.com (M.W.); guoliangli@cau.edu.cn (G.L.); xiaohuanlu111@163.com (X.L.); wangming7273@163.com (M.W.); shaoj@cau.edu.cn (S.C.)

2 Key Laboratory of Plant-Soil Interaction, the Ministry of Education, Center for Resources, Environment and Food Security, College of Resources and Environmental Sciences, China Agricultural University, Beijing 100193, China; chenz9418@163.com (Z.C.); caucfj@cau.edu.cn (F.C.); yuanlixing@cau.edu.cn (L.Y.)

3 State Plant Breeding Institute, University of Hohenheim, 70593 Stuttgart, Germany; willmar_leiser@uni-hohenheim.de (W.L.L.); theami.weiss@uni-hohenheim.de (T.M.W.)

4 Institute of Plant Breeding, Seed Science and Population Genetics, University of Hohenheim, 70593 Stuttgart, Germany; tobias.wuerschum@uni-hohenheim.de

5 Institute of Crop Science, Chinese Academy of Agricultural Sciences, Beijing 100081, China

* Correspondence: wenxinliu@cau.edu.cn; Tel.: +86-010-6273-4984

+ These authors contributed equally to this work.

Abstract: Phosphorus (P) deficiency is an important challenge the world faces while having to increase crop yields. It is therefore necessary to select maize (Zea may L.) genotypes with high phosphorus use efficiency (PUE). Here, we extensively analyzed the biomass, grain yield, and PUE-related traits of 359 maize inbred lines grown under both low-P and normal-P conditions. A significant decrease in grain yield per plant and biomass, an increase in PUE under low-P condition, as well as significant correlations between the two treatments were observed. In a genome-wide association study, 49, 53, and 48 candidate genes were identified for eleven traits under low- $\mathrm{P}$, normal-P conditions, and in low-P tolerance index (phenotype under low-P divided by phenotype under normal-P condition) datasets, respectively. Several gene ontology pathways were enriched for the genes identified under low-P condition. In addition, seven key genes related to phosphate transporter or stress response were molecularly characterized. Further analyses uncovered the favorable haplotype for several core genes, which is less prevalent in modern lines but often enriched in a specific subpopulation. Collectively, our research provides progress in the genetic dissection and molecular characterization of PUE in maize.

Keywords: maize; P stress; phosphorus use efficiency; genome-wide association study; gene ontology analysis; phylogenetic characterization

\section{Introduction}

Maize is a multi-purpose crop, being an important staple food, feed, and industrial raw material. It is very important to ensure stable maize production. Phosphorus $(\mathrm{P})$ is a major element necessary for plant growth and development. P deficiency is an important abiotic stress that limits crop yield [1,2]. Around the world, cropland in many regions is in a state of P deficiency, especially in developing countries [3]. Generally, farmers solve the problem of soil P deficiency by applying chemical fertilizers. However, excessive application and $\mathrm{P}$ deposition into rivers has led to the low use efficiency of $\mathrm{P}$ fertilizers, which causes 
many ecological and environmental problems [4,5]. At the same time, phosphate rock, a non-renewable resource, is expected to be depleted in the next 100-400 years [6]. Therefore, it is critical to identify genotypes that have high P use efficiency (PUE, defined as the yield produced per unit of $\mathrm{P}$ available in the soil) and thus obtain a higher yield under $\mathrm{P}$ deficient conditions, by applying molecular breeding methods based on genetic analysis of PUE [7].

Under P stress, plants show a series of P starvation responses to ensure normal growth. For example, plants change root structure, membrane structure, release more organic acids and enzymes like phosphatases and phytases, and regulate the expression of P starvation response genes [2,8], involving the transcriptome, proteome, metabolome, and other levels. This eventually leads to changes in the physiological and morphological characteristics of plants, such as the accumulation of anthocyanins [9,10], root characteristics [11,12], plant height $[13,14]$, biomass, and yield $[13,15]$. Therefore, the absorption and utilization of $\mathrm{P}$ in plants is regulated by a complex genetic network. These changes at the phenotypic and molecular level are the basis for analyzing the genetic mechanism of PUE. At the same time, plant height, biomass, and yield are suitable for screening potential low-P tolerant genotypes, and for genetic analyses.

In Arabidopsis, rice, and other crops, great progress has been made in understanding the mechanism of $\mathrm{P}$ regulation. For example, phosphate transporters are responsible for phosphate uptake and allocation [16]; ARF7 and ARF19 positively regulate the $\mathrm{P}$ starvation response [17]; PHR1 regulates lipid remodeling during P starvation [18]; ZAT6 synchronizes P homeostasis and root development [19]; PSTOL1 is an enhancer of early root growth [20]; BHLH32 has a negative effect on anthocyanin accumulation, root hair formation, and cellular $\mathrm{P}$ concentration [21,22]; the miR399-PHO2 pathway [23] regulates the distribution of $\mathrm{P}$ in plants. In maize, some microRNA, such as Zma-miR3 [24] and miR399 [25], were identified in seedling roots under low-P condition; PILNCR1-miR399 interaction and the miR399-PHO2 regulatory pathway have different modes of action in maize inbred lines with different PUE [26]; transcription factor NIGT1.2 increases the absorption of $\mathrm{P}$ but decreases the absorption of $\mathrm{NO}_{3}^{-}$during $\mathrm{P}$ starvation, similar to the regulatory pathway in Arabidopsis [27]; transcription factor ZmPHR1 can improve PUE under P-deficient conditions [28]. However, most genes were identified or confirmed through reverse genetics. Hence, there is an urgent need to identify the genes underlying natural variation through forward genetics.

Many quantitative trait loci (QTL) related to PUE have been detected in a wide range of genetic populations [29] using root-related traits [30-32], biomass-related traits [33], and yield-related traits [34,35]. Among them, the research and utilization of the locus Pup1, named phosphorus-starvation tolerance 1 (PSTOL1), was the most successful, and its overexpression was shown to increase the biomass and yield of rice under low-P condition [20]. The homologous regions of rice PSTOL1 in sorghum increase biomass and have an important role in the root system under low-P condition [36], and also play a similar part in maize [33]. In maize, Zhang et al. [34] mapped a major QTL $q K N$ controlling kernel number per row under different P conditions; Qiu et al. [37] identified QTL AP9, which is related to acid phosphatase activity under P deficiency; and Mendes et al. [38] explored the genetic architecture of PUE in tropical maize using recombinant inbred lines (RILs).

In recent years, genome-wide association study (GWAS) has become a powerful tool for analyzing the genetic basis of complex traits in maize [39]. Xu et al. [35] conducted a GWAS of 18 traits under two P levels combined with RNA-seq data of extreme genotypes under P stress and identified 259 candidate genes, mainly involved in four pathways: transcriptional regulation, reactive oxygen scavenging, hormone regulation, and remodeling of the cell wall. Luo et al. [40] conducted their GWAS on 22 root-related phenotypes under two P levels at the seedling stage and combined them with the metabolomic data of extreme inbred lines; through this, three potential candidate genes GRMZM2G039588, GRMZM5G841893, and GRMZM2G051806 were found, and several were confirmed in RILs. Similarly, Wang et al. [31] used 13 root-related phenotypes at different P levels at the seedling stage to perform GWAS combined with transcriptome data and identified 
the candidate gene GRMZM2G009544, which is closely associated with several root traits, namely total root length, root forks (a measure of root branching), and the total number of root tips. These previous studies have shown that GWAS has great potential to be used in excavating candidate genes for maize P-related traits. The above studies mainly focused on root architecture or some visible traits at the seedling stage; however, for the internal $\mathrm{P}$ utilization in shoot, kernel, and grain yield at maturity stage in the association panel, to our knowledge, there is no report in maize until now.

In our study, the GWAS was conducted for an association panel containing 359 inbred lines for PUE, biomass, and yield-related traits under normal-P and low-P treatments in the field. The main objectives were as follows: (1) to explore the variation and relationship of traits under normal-P and low-P environments, (2) to identify candidate genes related to $P$ stress response and PUE, (3) to identify conserved protein motifs and cis-elements of major candidate genes, and (4) to identify favorable haplotypes of genes related to PUE. Our research showed abundant and stable genetic variation in traits under P deficiency. Dozens of genes were identified by GWAS. Furthermore, several key candidates were mined and haplotype frequencies were explored to provide a strategy for molecular breeding of P-efficient lines.

\section{Results}

\subsection{Phenotypic Variation under Low-P and Normal-P Conditions}

Traits of an association panel consisting of 359 inbred lines were recorded under low-P and normal-P treatments in the field with the available P concentration in the soil around $2.1 \mathrm{mg} / \mathrm{kg}$ and $4.5 \mathrm{mg} / \mathrm{kg}$, respectively. Wide variations of eleven traits were observed under the two P treatments (Table 1). Significant differences under low-P and normal-P conditions were detected for all traits. (Figure 1 and Figure S1). P utilization efficiency (PUtE) had an increase, especially shoot P utilization efficiency (ShPUtE) which increased by $55.0 \%$; however, the remaining traits showed a significant decrease when comparing low-P to normal-P conditions. The various impact of $\mathrm{P}$ on plant growth was well shown in two traits. Yield per plant (YPP) was reduced by $68.3 \%$, whereas seed $\mathrm{P}$ concentration (SePCc) showed only a slight reduction in low-P versus normal-P condition. The correlations of all traits were positively significant between the two $\mathrm{P}$ conditions. The highest correlation was observed for shoot dry weight per plant (SDWPP) $(r=0.69$, $p<0.01)$, and the lowest for seed P utilization efficiency (SePUtE) $(r=0.36, p<0.01)$. For YPP, this correlation was $0.67(p<0.01)$.

Under the low-P condition, the genetic variances of yield-related and biomass-related traits were generally increased (Table 1 ) compared to the normal-P condition regarding the genetic coefficient of variation $(\mathrm{GCV})$. The variance of genotype-by-P treatment interaction $\left(\sigma_{G \times T}^{2}\right)$ was only significant $(p<0.01)$ for SePCc, shoot P concentration (ShPCc), SePUtE, and ShPUtE. For all traits, the genetic variance component $\sigma_{G}^{2}$ was larger than the $\sigma_{G \times T}^{2}$. The repeatability was slightly higher under normal-P compared to the low-P condition for most traits, ranging from 0.34 for SePUtE under low-P to 0.72 for ShPCc under normal-P (Table 1). For YPP, the repeatability was 0.67 and 0.57 under low-P and normal-P conditions, respectively. The genetic variance across both $\mathrm{P}$ conditions was significant $(p<0.01)$ for all traits, and broad-sense heritability ranged between 0.47 for SePUtE to 0.77 for SDWPP. The heritability of YPP was high, reaching 0.69 .

The correlations among eleven traits in low-P, normal-P, and the derived low-P tolerance index (LPTI) (estimated as phenotype under low-P divided by phenotype under normal-P) datasets were used to perform correlation analysis (Figures 2 and S2). In the low$P$ dataset (Figure 2A), ShPUtE was significantly correlated with biomass $(r=0.2$ for SDWPP and $r=0.24$ for all dry weight per plant (ADWPP)) and with YPP $(r=0.34)$, which was also significantly correlated with SePUtE $(r=0.3)$ and seed P content per plant (SePCPP) $(r=$ $0.3)$. For YPP under the low-P condition, SePUtE showed a significantly positive correlation $(r=0.31)$, but ShPCc and SePCc both showed significantly negative correlations, -0.3 and -0.3 , respectively. In the normal-P dataset, ShPUtE also significantly correlated with YPP, 
SDWPP, and ADWPP, with coefficients $0.38,0.19$, and 0.35 , respectively (Figure $2 \mathrm{~B}$ ). In the LPTI datasets, ShPUtE showed a slightly positive correlation $(r=0.2)$ with YPP and SDWPP $(r=0.11)$, but was not significantly positively correlated with ADWPP (Figure S2). In addition, we also observed a significant correlation between ShPUtE and SePUtE under the low-P condition (Figure 2A), but this could not be seen in the normal-P (Figure 2B) and LPTI dataset (Figure S2). A high correlation between different traits meant they had similar change patterns under each condition. In addition, significant correlations between ShPUtE with yield and biomass highlighted its important role.

Table 1. Summary statistics of all traits under the two P conditions.

\begin{tabular}{|c|c|c|c|c|c|c|c|c|c|c|c|}
\hline Traits & P-Level & Mean & SD & $r$ & Rd (\%) & $\sigma_{G}^{2}$ & $R e p^{2}$ & $\sigma_{G-a c r}^{2}$ & $\sigma_{G \times T}^{2}$ & GCV & $H^{2}$ \\
\hline YPP & $\mathrm{LP}$ & 2.47 & 3.55 & $0.67^{* *}$ & 68.3 & $46.7^{* *}$ & 0.67 & $11.0^{* *}$ & 0.00 & 2.764 & 0.69 \\
\hline YPP & NP & 7.80 & 7.91 & & & $68.1^{* *}$ & 0.57 & & & 1.058 & \\
\hline SDWPP & LP & 46.7 & 21.5 & $0.69^{* *}$ & 34.0 & $501.1^{* *}$ & 0.64 & $338.9 * *$ & 9.38 & 0.479 & 0.77 \\
\hline SDWPP & NP & 70.8 & 26.9 & & & $701.9^{* *}$ & 0.64 & & & 0.374 & \\
\hline ADWPP & LP & 54.3 & 27.9 & $0.62^{* *}$ & 36.3 & $1022.2 * *$ & 0.68 & $523.4^{* *}$ & 14.27 & 0.589 & 0.72 \\
\hline ADWPP & $\mathrm{NP}$ & 85.2 & 33.6 & & & $1280.7^{* *}$ & 0.64 & & & 0.420 & \\
\hline $\mathrm{SePCc}$ & LP & 3.46 & 0.45 & $0.42^{* *}$ & 3.49 & $0.085^{* *}$ & 0.41 & $0.061^{* *}$ & $0.016^{* *}$ & 0.084 & 0.50 \\
\hline SePCc & NP & 3.58 & 0.40 & & & $0.076^{* *}$ & 0.45 & & & 0.077 & \\
\hline ShPCc & $\mathrm{LP}$ & 1.13 & 0.22 & $0.56^{* *}$ & 35.7 & $0.029^{* *}$ & 0.61 & $0.031^{* *}$ & $0.011^{* *}$ & 0.149 & 0.65 \\
\hline ShPCc & NP & 1.76 & 0.37 & & & $0.10^{* *}$ & 0.72 & & & 0.182 & \\
\hline SePCPP & LP & 12.0 & 14.0 & $0.66^{* *}$ & 60.0 & $395.9^{* *}$ & 0.53 & $153.1^{* *}$ & 0.80 & 1.658 & 0.53 \\
\hline SePCPP & NP & 30.0 & 29.3 & & & $918.8^{* *}$ & 0.60 & & & 1.010 & \\
\hline ShPCPP & $\mathrm{LP}$ & 51.5 & 24.5 & $0.55^{* *}$ & 58.2 & $463.9^{* *}$ & 0.50 & $353.4^{* *}$ & 0.00 & 0.419 & 0.63 \\
\hline ShPCPP & NP & 123.2 & 52.8 & & & $1704.5^{* *}$ & 0.48 & & & 0.335 & \\
\hline АРCPP & $\mathrm{LP}$ & 73.2 & 37.0 & $0.52 * *$ & 53.3 & $1238.5^{* *}$ & 0.53 & $1001.9 * *$ & 127.9 & 0.481 & 0.54 \\
\hline APCPP & NP & 156.7 & 67.9 & & & $4276.4^{* *}$ & 0.57 & & & 0.417 & \\
\hline SePUtE & LP & 0.29 & 0.04 & $0.36^{* *}$ & -3.31 & $0.00063^{* *}$ & 0.34 & $0.00038^{* *}$ & $0.00014^{* *}$ & 0.086 & 0.47 \\
\hline SePUtE & NP & 0.28 & 0.03 & & & $0.00062 * *$ & 0.50 & & & 0.088 & \\
\hline ShPUtE & LP & 0.92 & 0.19 & $0.56^{* *}$ & -55.0 & $0.024^{* *}$ & 0.43 & $0.0099 * *$ & $0.0028 * *$ & 0.166 & 0.70 \\
\hline ShPUtE & NP & 0.60 & 0.13 & & & $0.011^{* *}$ & 0.60 & & & 0.178 & \\
\hline APUtE & LP & 0.86 & 0.17 & $0.46^{* *}$ & -49.4 & 0.013 & 0.50 & $0.0057^{* *}$ & 0.00038 & 0.130 & 0.62 \\
\hline APUtE & $\mathrm{NP}$ & 0.57 & 0.10 & & & $0.0065 *$ & 0.65 & & & 0.135 & \\
\hline
\end{tabular}

SD: Standard deviation; $r$ : Correlation coefficient between low-P (LP) and normal-P treatment (NP); Rd (\%): Relative reduction under low-P stress calculated by (mean (NP)-mean (LP))/mean (NP); Rep $p^{2}$ : Repeatability in each treatment; $\sigma_{G-a c r}^{2}$ : Genetic variance across both P conditions; GCV: Genetic coefficient of variation calculated as $\operatorname{sqrt}\left(\sigma_{G}^{2}\right) /$ mean; $H^{2}$ : Broad-sense heritability. *: Significant at 0.05 level, **: Significant at 0.01 level. YPP (g): Yield per plant; SDWPP $(\mathrm{g})$ : Shoot dry weight per plant; ADWPP (g): All dry weight per plant; SePCc (mg/g): Seed P concentration; ShPCc (mg/g): Shoot P concentration; SePCPP (mg): Seed P content per plant; ShPCPP (mg): Shoot P content per plant; APCPP (mg): All P content per plant; SePUtE (g/mg): Seed P utilization efficiency, calculated by the inverse of SePCc; ShPUtE (g/mg): Shoot P utilization efficiency, calculated by the inverse of ShPCc; APUtE $(\mathrm{g} / \mathrm{mg})$ : All P utilization efficiency, calculated by ADWPP divided by APCPP.

\subsection{Traits Distribution of Different Subpopulations under Low-P Condition}

Based on a previous study [41], our 359 maize inbred lines were clustered into four subpopulations, namely non-stiff stalk (NSS), stiff stalk (SS), tropical and subtropical (TST), and mixed. To explore the phenotypic differences of these four groups under the low-P treatment, multiple comparisons were conducted. For SePUtE, there was not a significant difference among the four subpopulations. For ShPUtE and all P utilization efficiency (APUtE), the SS subpopulation showed significantly higher trait values than NSS, and slightly but not significantly higher values than TST and mixed subpopulations, which means that those lines within SS generally use the absorbed $\mathrm{P}$ in a more efficient way than other subpopulations under P deficient conditions (Figure 3). The TST subpopulation showed higher values for ADWPP (Figure S3C) and SDWPP (Figure S3E), which indicates that this group generally produced more biomass under low-P conditions, pointing to a higher $\mathrm{P}$ uptake efficiency. For the remaining traits, there was no significant difference (Figure S3A,B,D). Therefore, these two subpopulations have the potential to breed lines with high $P$ uptake efficiency and $P$ utilization efficiency. 

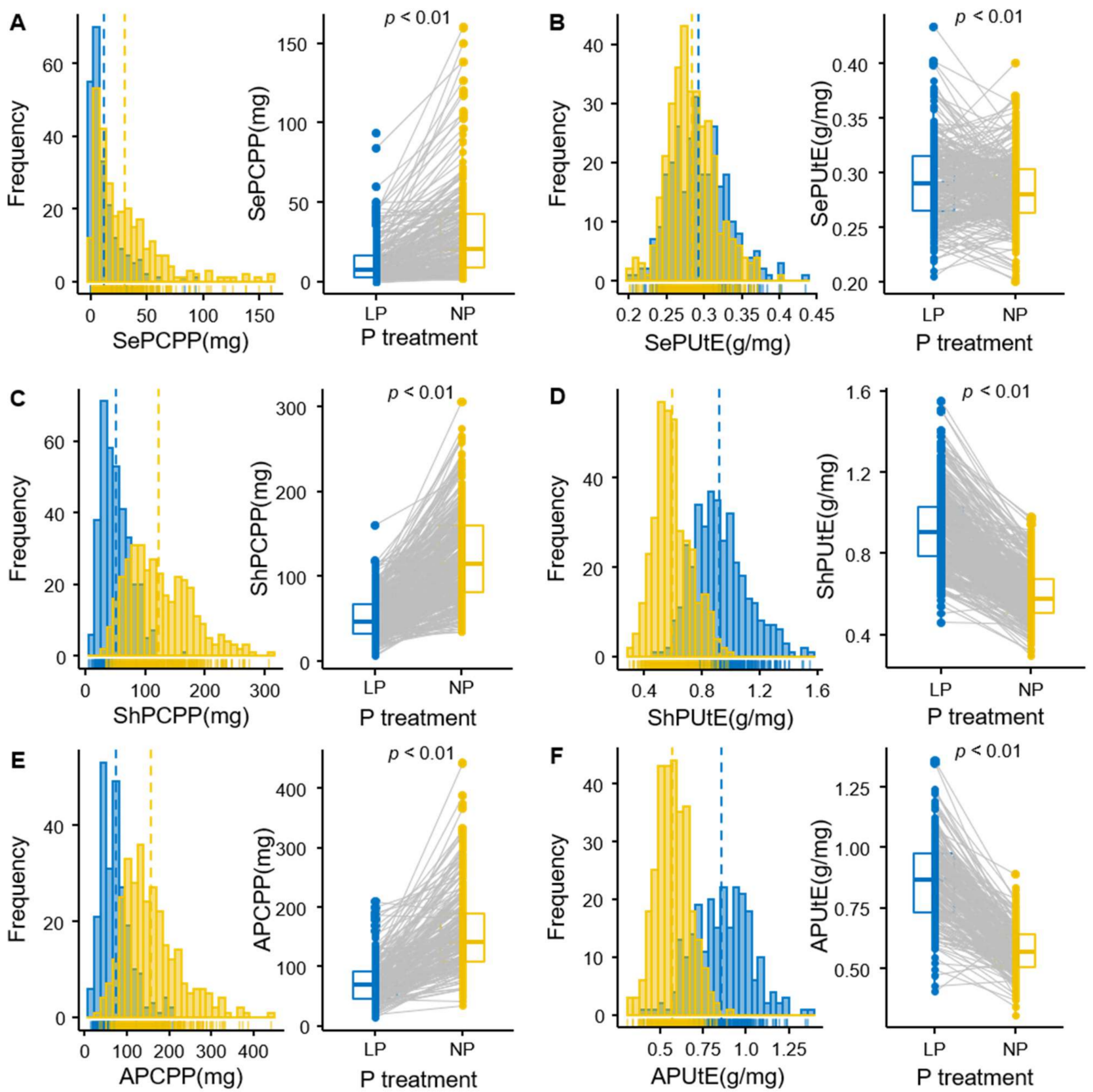

Figure 1. Distribution and interaction of traits under low-P and normal-P treatments. (A) SePCPP. (B) SePUtE. (C) ShPCPP. (D) ShPUtE. (E) APCPP. (F) APUtE. SePCPP: Seed P content per plant; SePUtE: Seed P utilization efficiency; ShPCPP: Shoot P content per plant; ShPUtE: Shoot P utilization efficiency; APCPP: P content per plant; APUtE: All P utilization efficiency. The significant difference was calculated by $t$-tests between the phenotypes under low-P and normal-P conditions for all traits.

\subsection{Genome-Wide Association Study to Identify P-Stress Responsive Genes}

Genome-wide association study (GWAS) was performed on the traits with the low-P, normal-P, and LPTI datasets (Figures S4-S6). We identified 92, 72, and 63 significant SNPs for eleven traits in the three datasets, respectively, and 49,53, and 48 candidate genes were identified in total (Tables 2 and S1). Gene annotations were obtained from MaizeGDB (https: / / www.maizegdb.org/, accessed on 9 June 2021). Besides, their homologous genes in Arabidopsis were obtained through BLASTP, and annotations were downloaded from TAIR (https: / / www.arabidopsis.org/, accessed on 9 June 2021). Seven key genes related to phosphate transporter proteins, abiotic stress response, root architecture, or members of the BHLH and F-BOX gene family are listed in Table 2 and the rest are listed in Table S1. 

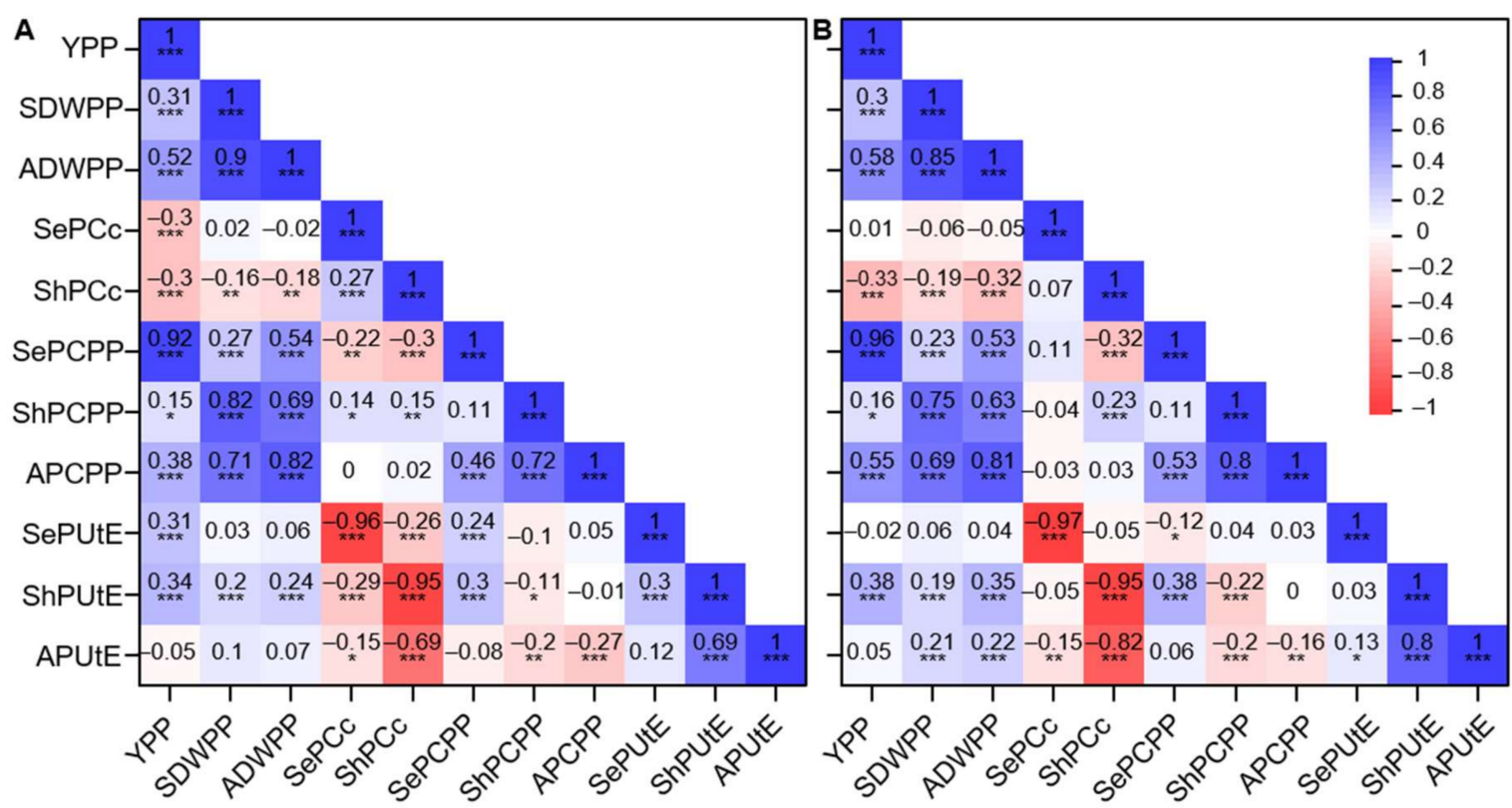

Figure 2. Correlations among eleven traits under low-P (A) and normal-P (B) conditions. YPP: Yield per plant; SDWPP: Shoot dry weight per plant; ADWPP: All dry weight per plant; SePCc: Seed P concentration; ShPCc: Shoot P concentration; SePCPP: Seed P content per plant; ShPCPP: Shoot P content per plant; APCPP: P content per plant; SePUtE: Seed P utilization efficiency; ShPUtE: Shoot P utilization efficiency; APUtE: All P utilization efficiency. ${ }^{*}: p<0.05 ;{ }^{* *}: p<0.01{ }^{* * *}: p<0.001$.

A significant SNP, namely chr5.S_31881708 $\left(-\log _{10}(P)=5.0\right)$, was found for ShPUtE under the low-P condition (Figure 4A,B). This SNP is at the exon of the gene GRMZM2G326707 (Figure 4C), and there was a significant difference $(p<0.01)$ between the two genotypes (Figure 4D). GRMZM2G326707 (ZmPHT1;1) encodes the phosphate transporter protein1 (PHT1) in maize [42]. The PHT1 gene family was widely studied in many crops and observed to play an important role in the phosphorus starvation response and PUE regulation $[25,43-45]$. Furthermore, four significant SNPs were found for ShPUtE under low-P condition, which were all located in the exon of the GRMZM5G848945 gene region (Figure S7). GRMZM5G848945 encodes protein F-BOX3, which is important in root development and stress responses $[46,47]$. Interestingly, there were two significant SNPs identified for LPTI of SePCc, and another gene, GRMZM2G155849, encoding the F-BOX3 protein was found (Table S1). In addition, the significant SNP chr8.S_162559636 found for SePCPP under low-P condition was located in the gene GRMZM2G030762 (Figure S8), which encodes the transcription factor $b H L H 55$, a member of BHLH family. In maize, transcription factor $b H L H 55$ can enhance plant salt stress through regulation of the biosynthesis of ascorbic acid, which is an antioxidant and enzyme vital to abiotic stress tolerance [48].

Besides, several genes were identified across different datasets. For example, common genes GRMZM2G171254 and GRMZM2G171277 were identified for several traits, particularly ShPUtE and ShPCc under the low-P condition, and APUtE, ShPCc, ShPUtE and YPP under the normal-P condition. In addition, GRMZM2G084296 was identified for SDWPP under low-P condition and SePUtE for LPTI.

\subsection{Gene Ontology Analysis}

The gene ontology (GO) enrichment analysis is an important method to understand gene functions. With a significant threshold of 4 , a total of 397 genes were identified in the low-P dataset. These genes were found to be involved in two significant GO terms $(p<0.05)$ in the biological process, namely "response to abiotic stimulus" and "stomatal movement", which showed that genes identified under the low-P condition are related to stress response (Figure 5A). Additionally, the other four significant terms in the cellular component, namely "organelle", "intracellular organelle", "membrane-bounded organelle", and "intracellular membrane-bounded organelle", are closely related to organelle (Figure 5B). The above re- 
sults show that stress response and organelle functional genes play an important role in the plant $P$ starvation response, which provided more information to confirm candidate genes.
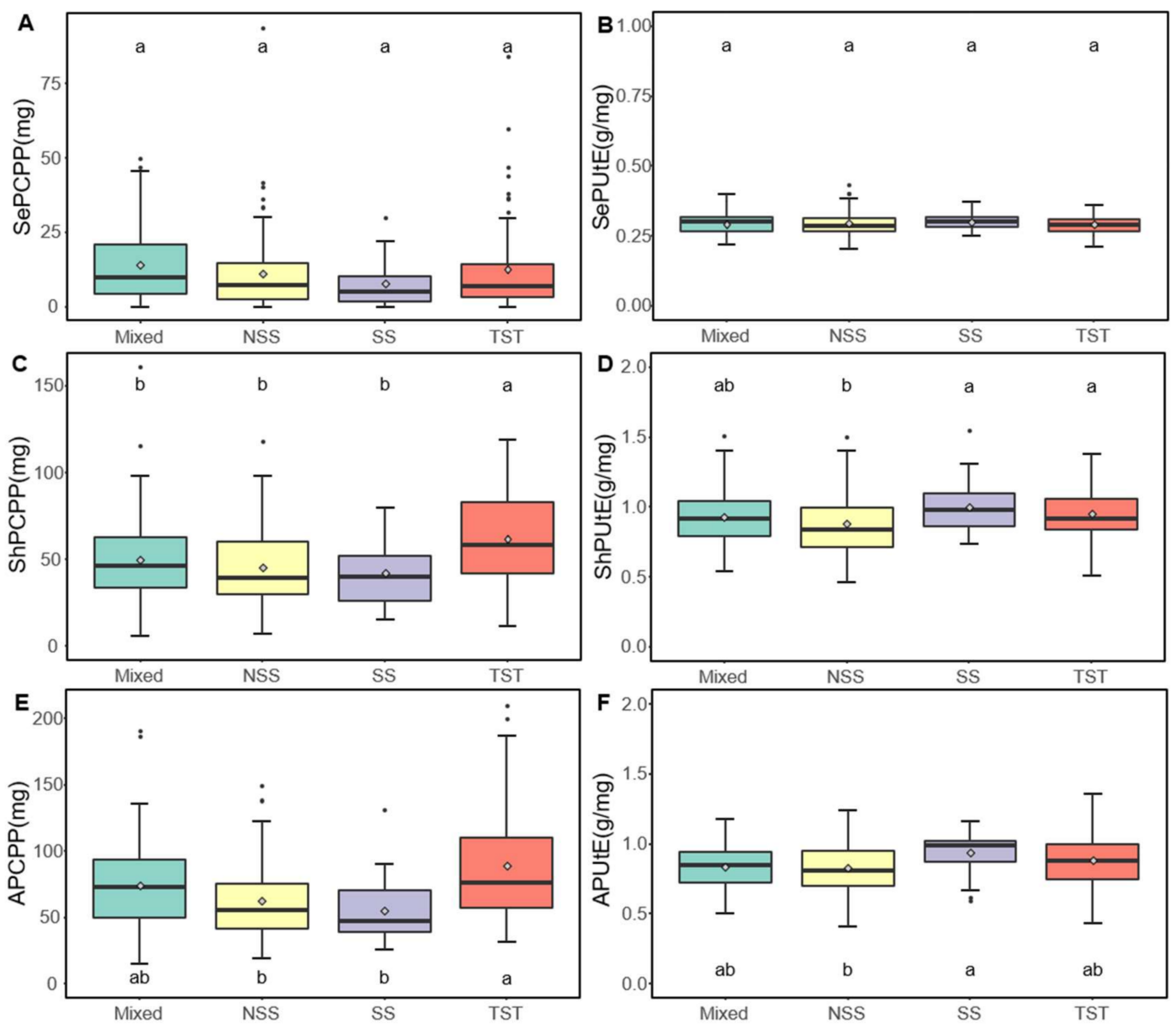

Figure 3. Boxplots for the performance of the four subgroups for six traits under low-P conditions. (A) SePCPP. (B) SePUtE. (C) ShPCPP. (D) ShPUtE. (E) APCPP. (F) APUtE. These four subpopulations are mixed $(n=101)$, non-stiff stalk (NSS, $n=118$ ), stiff stalk (SS, $n=29$ ), tropical/subtropical (TST, $n=111$ ). Multiple comparisons were conducted by the LSD test method at a 0.05 significance level. Different letters represent significant differences. The rhombus in the boxplot is the mean value. SePCPP: Seed P content per plant; SePUtE: Seed P utilization efficiency; ShPCPP: Shoot P content per plant; ShPUtE: Shoot P utilization efficiency; APCPP: P content per plant; APUtE: All P utilization efficiency.

\subsection{Phylogenetic Characterization and Cis-Elements Prediction of PHT1 Gene Family}

GRMZM2G326707 (ZmPHT1;1) encoding a phosphate transporter protein and a member of the PHT1 gene family was identified in ShPUtE under the low-P condition. Phosphate transporters are responsible for phosphate uptake and allocation in the plant [16], and play an important role under low-P stress [49]. We collected 46 possible members of the PHT1 gene family, 13 genes in maize (Zea mays L.), 13 genes in rice (Oryza sativa L.), 11 genes in sorghum (Sorghum bicolor L.), and 9 genes in Arabidopsis (Arabidopsis thaliana L.). A neighbor-joining tree was constructed using protein sequences (Figure 6). In total, 10 conservative motifs were identified. The PHT1 proteins shared high similarity and common motifs. Clear subfamilies could not be observed in spite of the species. In the dicot Arabidopsis, several genes were grouped into a subgroup, clearly showing the difference in differentiation between dicot and monocot species. In addition, the cis-elements analysis taking the DNA sequences upstream $1 \mathrm{~kb}$ of the transcriptional start site as a target identified some cis-elements related to hormones and stress. For example, ARE is involved in abscisic acid responsiveness, LTR is involved in low-temperature responsiveness, and TC-rich repeats are involved in defense and stress responsiveness. 
Table 2. Key candidate genes identified in the low-P, normal-P, and LPTI datasets, and homologous genes annotations in Arabidopsis thaliana.

\begin{tabular}{|c|c|c|c|c|c|c|}
\hline Condition & Traits & $\begin{array}{l}\text { Candidate } \\
\text { Genes }\end{array}$ & $\begin{array}{l}\text { Description } \\
\text { in Maize }\end{array}$ & $\begin{array}{c}\text { Homologous } \\
\text { Genes in Arabidopsis }\end{array}$ & $\begin{array}{l}\text { Other Names in } \\
\text { Arabidopsis }\end{array}$ & $\begin{array}{c}\text { Descriptions } \\
\text { in Arabidopsis in TAIR Website }\end{array}$ \\
\hline \multirow{4}{*}{ low-P } & \multirow{3}{*}{$\begin{array}{l}\text { ShPUtE } \\
\text { ShPUtE }\end{array}$} & GRMZM2G326707 & Phosphate transporter protein 1 & AT2G38940 & PHT1;4 & $\begin{array}{l}\text { The expression is upregulated in the shoot of } \\
\text { cax1/cax3 mutant and is responsive to } \\
\text { phosphate (Pi) and not phosphite (Phi) in roots } \\
\text { and shoots. }\end{array}$ \\
\hline & & \multirow[t]{2}{*}{ GRMZM5G848945 } & \multirow[t]{2}{*}{ Protein AUXIN SIGNALING F-BOX 3} & AT3G26810 & $A F B 2$ & \multirow{2}{*}{$\begin{array}{c}\text { The dominant auxin receptor in roots. } \\
\text { Auxin receptor involved in primary and lateral } \\
\text { root growth inhibition in response to nitrate. } \\
\text { The target of miR393. Induced by nitrate in } \\
\text { primary roots. }\end{array}$} \\
\hline & & & & AT1G12820 & AFB3 & \\
\hline & SePCPP & GRMZM2G030762 & Transcription factor bHLH55 & AT3G07340 & $\begin{array}{c}\text { CRY2-INTERACTING } \\
\text { BHLH } 3\end{array}$ & A bHLH DNA-binding superfamily protein. \\
\hline \multirow[t]{2}{*}{ normal-P } & ADWPP & GRMZM2G109967 & $\begin{array}{l}\text { CDP-diacylglycerol-glycerol-3-phosphate } \\
\text { 3-phosphatidyltransferase }\end{array}$ & AT2G39290 & $\begin{array}{c}\text { PHOSPHATID } \\
\text { YLGLYCEROLPHOSPHATE } \\
\text { SYNTHASE } 1\end{array}$ & \multirow{2}{*}{$\begin{array}{l}\text { Encodes a phosphatidylglycerol phosphate } \\
\text { synthase } 2 \mathrm{C} \text { which is dual-targeted into } \\
\text { chloroplasts and mitochondria. Mutant plants } \\
\text { have mutant chloroplasts but normal } \\
\text { mitochondria. } \\
\text { A phosphatidylinositol- } \\
\text { 4-phosphate phosphatase required for root } \\
\text { hair development. }\end{array}$} \\
\hline & SePCPP & GRMZM2G418916 & Phosphoinositide phosphatase SAC6 & AT3G51460 & ROOT HAIR DEFECTIVE4 & \\
\hline \multirow{3}{*}{ LPTI } & $\begin{array}{l}\text { ShPCc, } \\
\text { ShPUtE }\end{array}$ & GRMZM2G076630 & Probable transcriptional regulator SLK2 & AT5G62090 & SLK2 & $\begin{array}{l}\text { Encodes a protein that functions with LUH to } \\
\text { promote Al binding to the root cell wall. }\end{array}$ \\
\hline & \multirow[t]{2}{*}{ YPP } & \multirow[t]{2}{*}{ GRMZM2G104125 } & $\begin{array}{l}\text { Calcium- } \\
\text { dependent protein }\end{array}$ & AT5G19450 & CDPK19 & \multirow{2}{*}{$\begin{array}{c}\text { Calcium-dependent protein kinase (CDPK19) } \\
\text { mRNA, complete. } \\
\text { Calmodulin-domain protein kinase CDPK } \\
\text { isoform } 7 .\end{array}$} \\
\hline & & & kinase 2 & AT5G12480 & CPK7 & \\
\hline
\end{tabular}



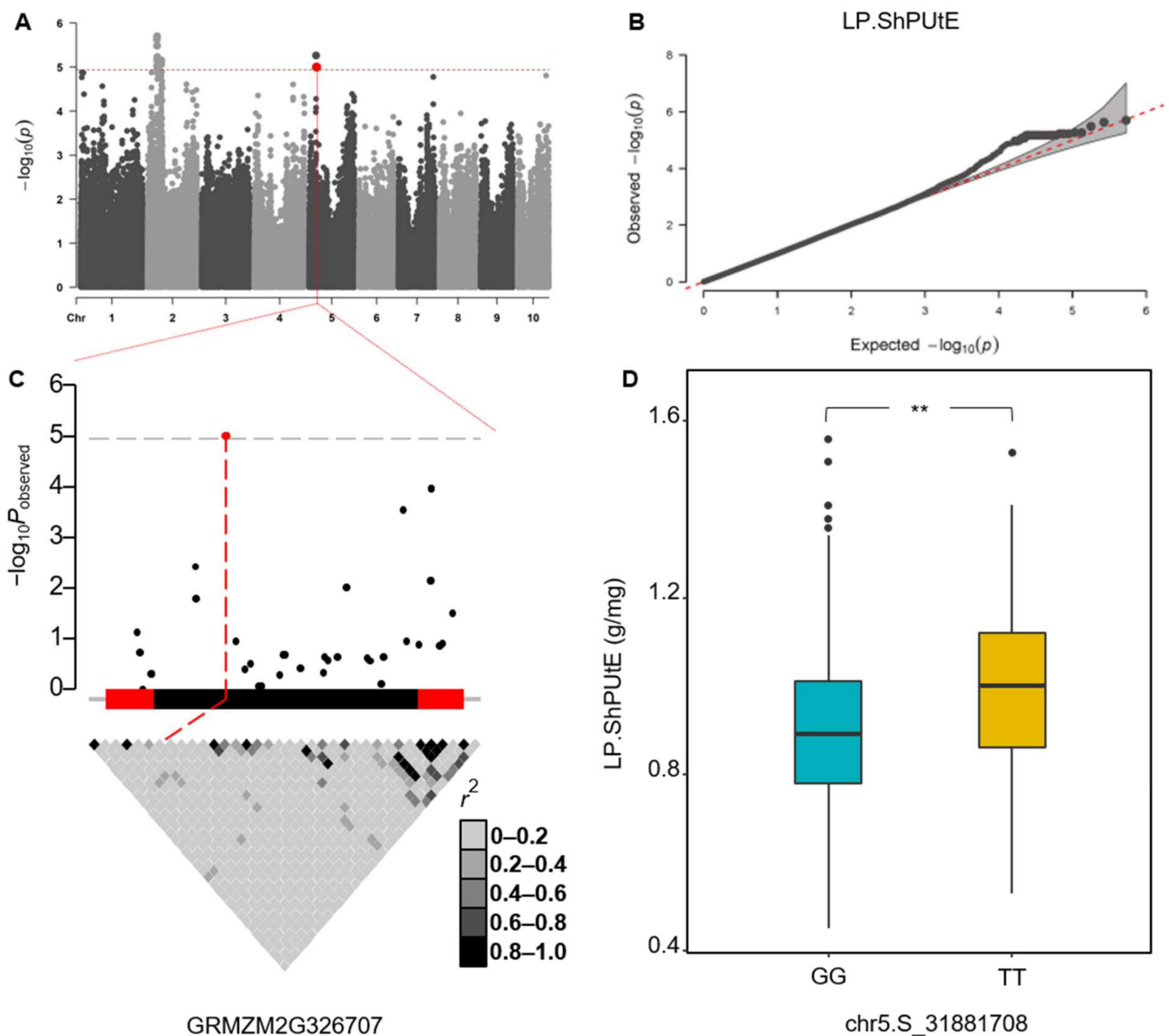

Figure 4. Manhattan (A) and quantile-quantile (B) plot for ShPUtE under low-P condition; gene structure of GRMZM2G326707 and pairwise linkage disequilibrium (LD) analysis (C); and the distribution of two genotypes for ShPUtE under the low-P condition in our population $(t$-test, $p<0.01)(D)$. The dotted line is the significance threshold of 4.94 . ShPUtE: Shoot P utilization efficiency. **: Significant at 0.01 level.

\subsection{Identification of Favorable Haplotype for Molecular Breeding among Different Subpopulations}

In order to establish a guide for screening P-efficient materials and illustrate the frequency distribution of favorable haplotypes in different subpopulations, we selected five important P starvation-related genes. Among these genes, GRMZM2G326707 and GRMZM5G848945 were candidate genes found for ShPUtE under low-P condition by GWAS performed in our study, while the others were homologs of P starvation-related genes or root architecture-related genes in Arabidopsis found in previous studies; GRMZM2G381709 is a homolog of $\mathrm{PHO} 2$ [50] related with Pi uptake and allocation remobilization, GRMZM2G088487 is a homolog of ARP6 [51] as an epigenetic modulator of some P-starvation response genes, and GRMZM2G054050 is a homolog of LPR1 [52] associated with root architecture [53]. Considering the important role of the ShPUtE part of PUE and significant correlations between yield and biomass (Figure 2), ShPUtE variations under the low-P condition of different haplotypes of five important genes were investigated (Figure 7A). Except for GRMZM2G381709, significant differences between favorable and the remaining haplotypes $(p<0.05)$ were observed. The proportions of favorable haplotypes varied 
between subpopulations and genes (Figure 7B). Generally, the proportions of favorable haplotypes were small, which indicated that there is still much space for improvement in modern inbred lines. For gene GRMZM2G054050, the SS subpopulation showed a large proportion of favorable haplotype, while the proportion of favorable haplotype in other subpopulations was relatively small. The distribution of the favorable haplotype of GRMZM2G381709 was also interesting, as it had a medium-to-high proportion in TST, mixed, and SS, but a small proportion in the NSS subpopulation (Figure 7A,B). Population differentiation resulted in the frequency of favorable genes among the different groups, and some germplasm resources harboring favorable haplotypes could be used to improve the other inbred lines.
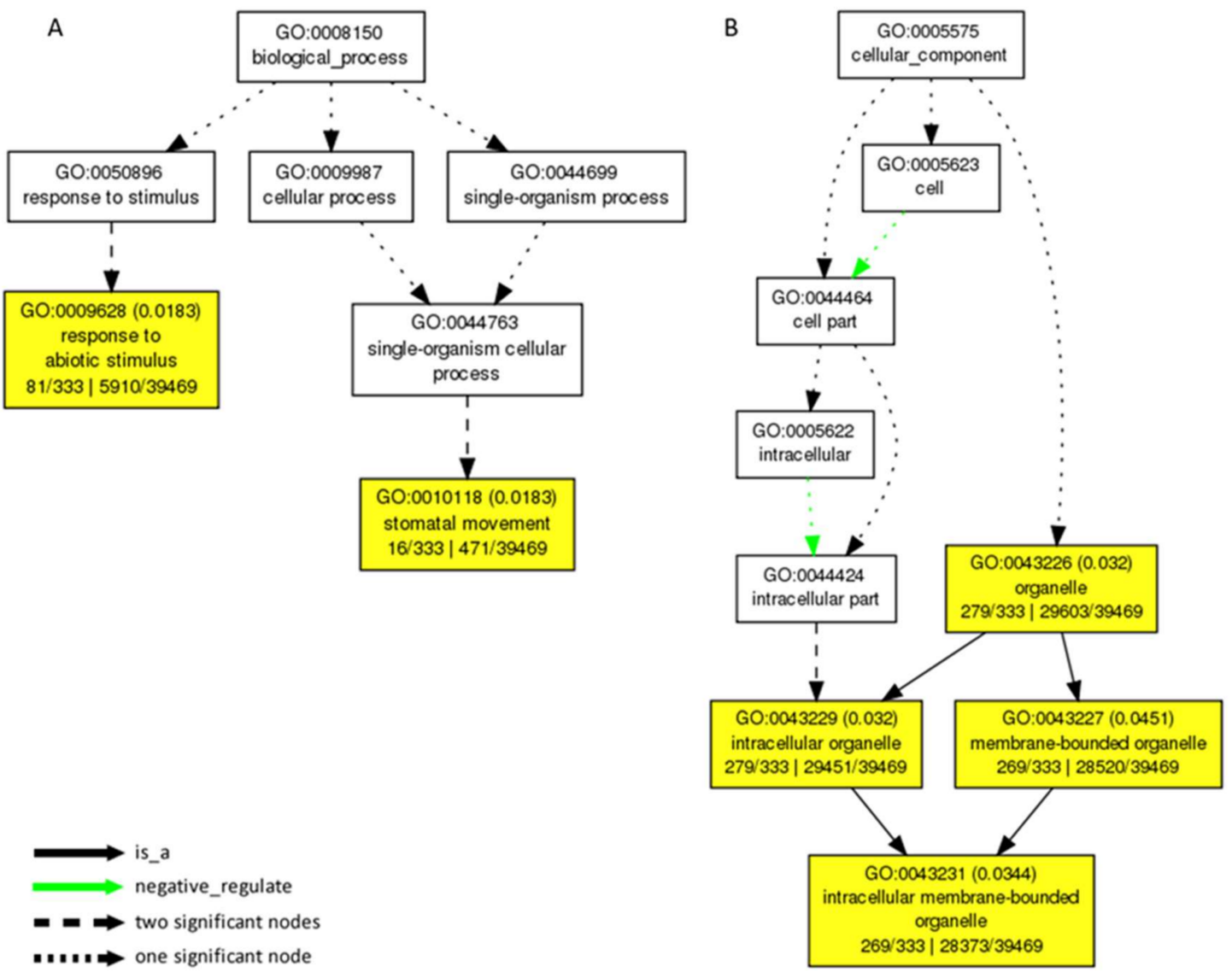

Figure 5. The significantly $(p<0.05)$ enriched GO terms for genes identified in GWAS under low-P condition with a significance threshold of 4. (A) Significant GO terms in the biological process. (B) Significant GO terms in the cellular component. The yellow rectangles represent significant GO terms $(p<0.05)$, and the green lines represent negative regulation. 


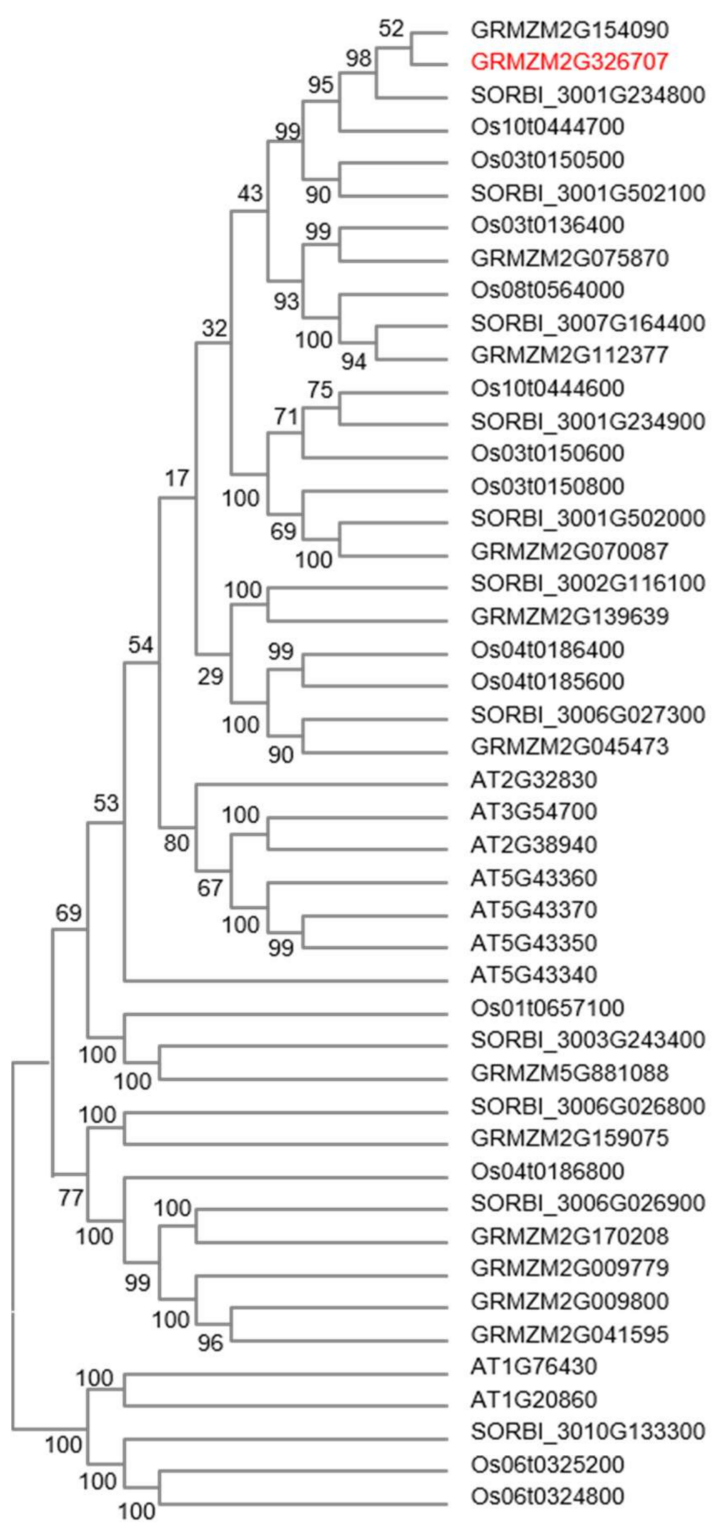

-

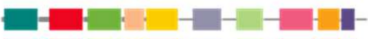

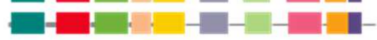

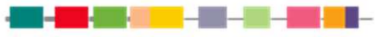
-

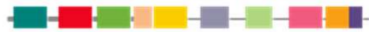

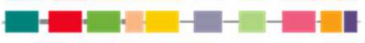

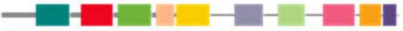

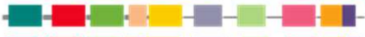

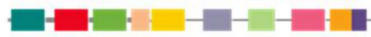

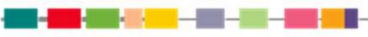

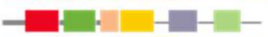

마마.

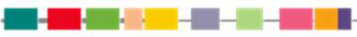
-

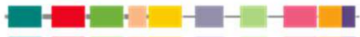
믈.

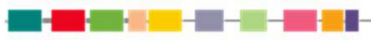

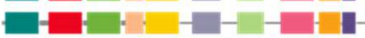

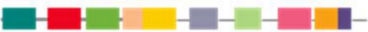

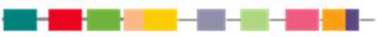
-

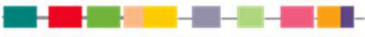

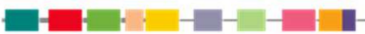

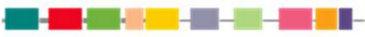
- -2.

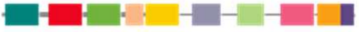

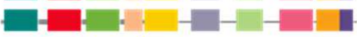
-

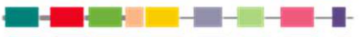

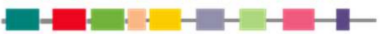

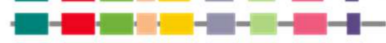
-1. - - - - - - $-\mathrm{a}-1-1-1-1$

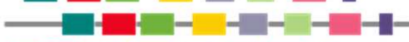
- $1-1-1-1$

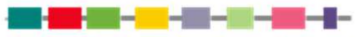
-10 - $-1-1-4$

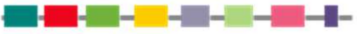
-4. - - - -

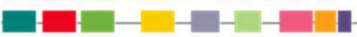
-

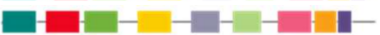

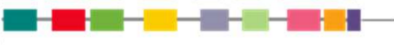
$5^{2}$

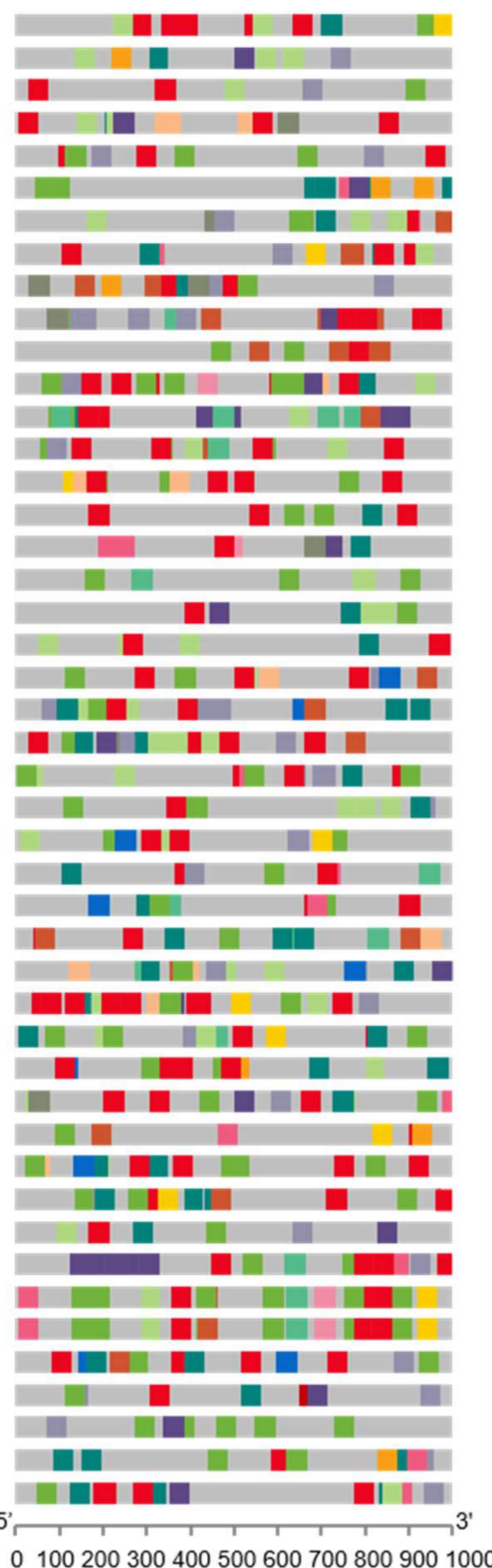

\begin{tabular}{|lll} 
Motif 1 & QLQVLSALDVAKTQWYHFTAIVIAGMGFFTDAYDLFCISLVTKLLGRIYY & MYC \\
Motif 2 & AAVNGVALCGTLAGQLFFGWLGDKLGRKRVYGMTLMLMVLCSVASGLSFG & TRE3 \\
Motif3 & MATLCFFRFWLGFGIGGDYPLSATIMSEYANKRTRGAFIAAVFAMQGFGI & ABRE \\
Motif 4 & VAJVVSAFRARFPAPAYADDPAASTVPQ & MYB \\
Motif5 & DYVWRIILMFGAVPAALTYYWRMKMPETARYTALVAKNAKQAAADMSKVL & MeJA-responsiveness \\
Motif6 & YGLFSRZFLRRHGLHLLGTTSTWFLLDIAFYSQNLFQKDIFSA & GC-motif \\
Motif7 & QTLIALCGTVPGYWFTVAFIDVVGRFIQLLGFFMMTVFML & ERE \\
Motif 8 & TFFFANFGPNSTTFIVPAEIFPARLRSTCHGISAAAGKAGAIVGAFGFLY & TCA-element \\
Motif9 & DKSKTDAGYPPGIGVRNSLFVLAGCNLLGFLFTF & W box \\
Motif 10 & LVPESKGKSLEEMSGENEDDE & WUN-motif \\
\hline
\end{tabular}

Figure 6. Polygenetic tree of PHT1 gene family and distribution of conserved motifs and potential cis-elements. The gene GRMZM2G326707 (ZmPHT1;1) in red was identified in our GWAS result. 
A

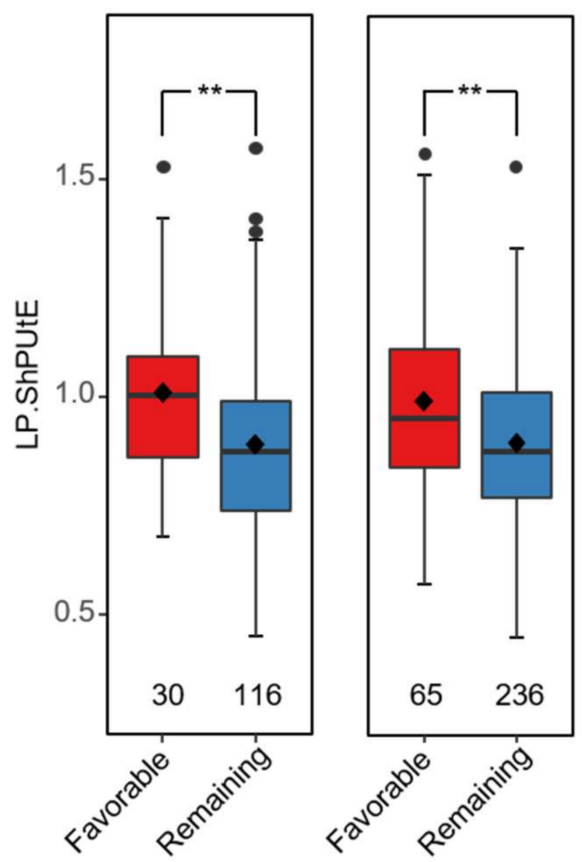

GRMZM2G381709 GRMZM2G088487

GRMZM2G054050

B
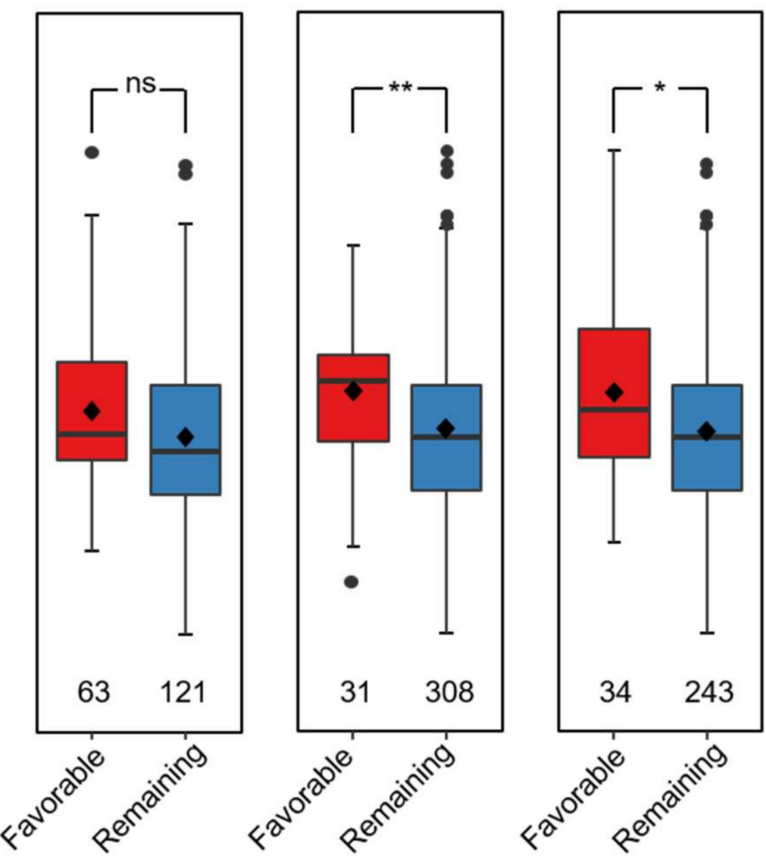

Mixed

NSS

SS

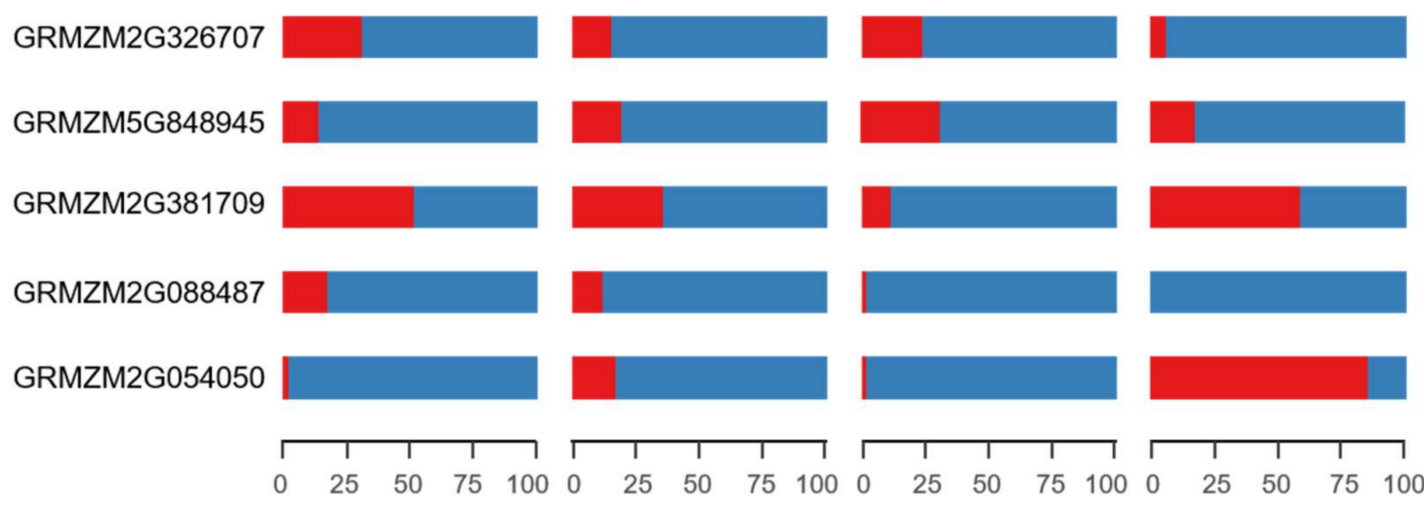

Favorable Hap frequency in subpopulations (\%)

Figure 7. ShPUtE variation under low-P condition and frequencies of the favorable haplotypes of five important low-P responsive genes. (A) Box plots for ShPUtE under low-P condition of favorable and remaining haplotypes. The numbers in the box plot represent the individual number. The significance test was done by $t$-test. *: Significant at 0.05 level; **: Significant at 0.01 level; ns: No significant difference. (B) The proportion of two types of haplotypes in four subgroups. Red represents the favorable haplotype and blue represents the remaining haplotype. ShPUtE: Shoot P utilization efficiency.

\section{Discussion}

PUE is an important and complex trait, which can be defined by grain yield per available $\mathrm{P}$ in soil and hence is affected by many genetic factors. PUE consists of two molecular processes, Pi uptake from soil to root and shoot called P uptake efficiency (PUpE), and internal Pi utilization named P utilization efficiency (PUtE). PUE (yield $/ \mathrm{P}_{\text {soil available }}$ ) $=\mathrm{PUpE}$ $\left(P_{t} / P_{\text {soil available }}\right) \times P U t E\left(\right.$ yield $\left./ P_{t}\right)$, where $P_{t}$ is the total $P$ in plant, and $P_{\text {soil available }}$ is the available $P$ in soil [15]. If using hydroponics, where precise $P$ is applied, the PUE can be calculated accurately for each genotype. Different from that, in this study we recorded traits in the field, where the PUE cannot be calculated accurately due to the heterogeneity of soil and other uncontrollable factors. However, PUtE can be calculated precisely by using a chemical method. Therefore, we mainly focused on PUtE, a component of PUE. Dissecting the genetic architecture of PUE and mapping potential genomic loci associated 
with PUE is the first step for a molecular breeding program. As far as we know, our study is the first large-scale evaluation and genetic dissection of PUE-related traits in a diverse set of maize.

\subsection{Phenotypic Variation for PUtE-Related, Yield and Biomass Traits under Two-P Levels}

Low-P stress has a great impact on plant growth and development (Figure 1). To explore the effects of low-P on maize, we mainly focused on: (1) biomass and yield-related traits, including ADWPP, SDWPP, and YPP; and (2) PUE-related traits, including SePUtE, ShPUtE, and APUtE. Total biomass (ADWPP) and grain yield (YPP) decreased under low-P condition by $36 \%$ and $68 \%$, respectively (Table 1 ). Such strong yield decreases show that there was a heavy $\mathrm{P}$ stress in our field. Thus, the genetic findings of this study may reflect actual PUE under severe $P$ deficiencies and may offer guidance to further understand PUE under severely depleted soils. Similar strong P effects have been shown by several authors. Cai et al. [54] observed a significant decrease in maize grain yield under low phosphorus conditions, with the yield of RILs reduced by about $37 \%$ compared to the control. Chen et al. [55] found a significant decrease in maize shoot dry weight and shoot total P accumulation. Similar to Yao et al. [56], we also observed an increased PUtE under low-P versus normal-P condition. This showed that the available $\mathrm{P}$ was more efficiently used under low-P condition versus well fertilized conditions. However, there was also a significant genetic variation for PUtE under the normal-P condition, pointing to the potential of selecting material, which utilizes the supplied P much better and hence could increase PUtE under well fertilized conditions as well, without sacrificing much yield (Figure 1). The correlation analysis showed the positive correlation coefficients between ShPUtE and biomass, as well as yield-related traits, which made it possible to select lines with high yield and high PUE simultaneously. In practice, lines with high PUE under different $P$ levels should be selected by plant breeders. We chose 20 lines with the highest APUtE under the low-P condition as P-efficient lines, namely "CIMBL91", “CIMBL106", “DAN599”, "GEMS56", “CIMBL15”, “CML415”, “07KS4", “CIMBL95", “CIMBL38”, “GEMS14", “GEMS24", “GY220”, “WH413”, “975-12”, "GEMS23", "CIMBL93", "GEMS9", "R08", "YU374", and "177". Among these 20 lines, "CML415", "CIMBL91", and "07KS4" also stood in the top 20 for APUtE under the normal$\mathrm{P}$ condition. Among these lines, there were six from NSS, three from SS, seven from TST, and four from the mixed subpopulation. In conclusion, PUE could be further improved in modern inbred lines. However, one needs to keep in mind that in order to translate it to actual PUE under farmers' conditions in which hybrid varieties normally grow, further evaluations of test-cross performances and the inheritance patterns of the determined traits are necessary.

\subsection{Key Candidate Genes for Low-P, Normal-P, and LPTI Datasets}

With the rapid development of sequencing technology, GWAS is becoming increasingly important for dissecting the genetic architecture of complex traits. As an allogamous crop, maize has a comparably rapid linkage disequilibrium (LD) decay and abundant diversity, so the mapping resolution can reach down to the gene level underlying QTL with millions of SNPs [57]. In our study, several key genes were identified that were also reported in former studies. The F-BOX3 protein encoded by the GRMZM5G848945 gene is an auxin receptor. Its homologous gene in rice is OsAFB2. The downregulation of OsAFB2 reduces the tolerance to salt stress and the sensitivity to auxin [58]. The homologous genes $A F B 2$ and $A F B 3$ in Arabidopsis are also closely related to plant abiotic stress [59]. GRMZM2G030762 encodes the transcription factor $b H L H 55$. The bHLH family participates in multiple biological processes in plants [60], especially playing an important role in dealing with drought stress [61,62].

The homologous gene of the candidate gene GRMZM2G109967 identified under normal-P in Arabidopsis is AT2G39290, which encodes phosphatidylglycerolphosphate synthase 1, being essential for the biosynthesis of phosphatidylglycerol in chloroplasts [63,64]. 
There is no doubt that AT2G39290 is important in maintaining the normal function of chloroplasts, and GRMZM2G109967 may have a similar function in maize with the relationship of phospholipids biosynthesis. For this, it is easy to understand that GRMZM2G109967 is associated with ADWPP. The homologous gene of GRMZM2G418916 in Arabidopsis is ROOT HAIR DEFECTIVE4, which relates to the normal development of plant root hairs [65]. The root hairs of plants play an important role in the absorption and utilization of nutrients [66], and GRMZM2G418916 corresponds with SePCPP. Both genes are important for the normal growth and development of plants.

We also identified some key candidate genes in the LPTI dataset. Among them, the homologous gene of GRMZM2G076630 in Arabidopsis is SLK2, related to the process of embryogenesis [67] and the response to abiotic stress [68]. GRMZM2G104125 encodes calcium-dependent protein kinase 2 (CDPK2), while the homologous gene in Arabidopsis encodes CDPK19. CDPKs play an important role in plant growth and development, stress response, and signal transduction [69]. Interestingly, phospholipids can regulate the activity of CDPK [70], so the environment of different phosphorus levels may affect the effect of CDPK. LPTI showed the phosphorus stress tolerance of plants, so genes corresponding with stress response would be concerned. These key candidate genes were reported to be functional under other stress conditions, and we think they are also associated with $\mathrm{P}$ stress based on our results. Besides the above key genes, some genes in Table S1 might be valuable in the future when progress has been made in functional genomics in maize, rice, and Arabidopsis.

\subsection{The Motif Compositions and Cis-Elements of the PHT1 Gene Family}

GRMZM2G326707 (ZmPHT1;1) encodes a PHT1 protein, which was associated with ShPUtE under the low-P condition. Previous studies have shown that the function of PHT1 is to transport phosphate into the maize shoot [16]. ZmPHT1;1 plays an important role in Pi uptake and redistribution in maize, and is induced during Pi starvation [49]. Besides, AtPHT1;4 promoter stimulates reporter gene expression in the monocot root system under low-P condition [71]. Most PHT1 genes are mainly expressed in roots and are upregulated under phosphorus starvation conditions [72]. Overexpression of OsPHT1;4 in rice increased phosphorus accumulation in plant roots and shoots [73]. The above result shows that the PHT1 family play an important role in the transport of Pi and the P starvation response in the plant. Therefore, it is necessary to explore the homologous genes and the conservative domain of the PHT1 protein family across the different crops.

With BLASTP using the protein sequence of GRMZM2G326707 (ZmPHT1;1) in maize as a query sequence, 13 genes were found in maize (Zea mays L.), 9 genes in Arabidopsis (Arabidopsis thaliana L.), 13 genes in rice (Oryza sativa L.), and 12 genes in sorghum (Sorghum bicolor L.). Based on a former study [74], a sorghum gene that did not contain the PHT1 specific signature (GGDYPLSATIxSE) was eliminated; in the end, 46 genes were left (Table S2). Generally, ten conservative motifs were identified in most proteins, and the distribution of motifs was also similar. The phylogenetic tree revealed that many shared motifs existed in the PTH1 sequence and a highly conservative protein sequence, especially in the dicot crop Arabidopsis. Previous studies have also mentioned that the protein sequences of the PHT1 genes were similar, and the expression patterns overlapped [75]. It also showed that the function of the PHT1 family was probably realized by these motifs, which lays the foundation for searching for the functional site of GRMZM2G326707.

Cis-elements play an important role in gene regulation [76] and gene action. The promoter sequences of these genes identified some wound and abiotic stress-responsive ciselements, such as ABRE, LTR, TC-rich repeats, and other hormone-responsive cis-elements. It illustrated that these genes were induced by abiotic stresses such as drought and hypoxia, and plant hormones such as abscisic acid and methyl jasmonate. Previous studies confirmed that some members in Arabidopsis were induced under the low-P condition [75], which pointed out the direction toward functional research on the members of the PHT1 gene family. 


\subsection{Imbalanced Distribution of Favorable Haplotypes among Different Subpopulations}

Maize originates from Mexico and has formed different groups under the domestication of humans, which shaped the wide phenotypic variation. During domestication, the frequency of favorable genetic fragments or genes changed due to genetic drift, mutation, and selection.

Many genes related to $\mathrm{P}$ uptake, utilization and translocation have been verified in many plants $[49,77,78]$. Therefore, it is very attractive to figure out the relationship between haplotype variation and PUE in the modern inbred lines. To explain this answer, in this study, two key genes identified in our GWAS and three published genes were taken as an example to define favorable haplotypes. One of five genes (GRMZM2G381709) was not significantly different between the favorable and the remaining haplotypes. Population structure may be one reason for this, which may explain why the gene was not identified in our GWAS. Some favorable genes were present at low frequency in all subpopulations but showed a high frequency in one subpopulation (Figure 7). This imbalanced distribution of favorable haplotypes illustrated that the proportion of some alleles could be further improved, and some alleles may be fixed in some subpopulations. Excellent lines with favorable haplotypes could be selected to improve other resources by introgression.

\subsection{Breeding P-Efficient Maize Lines}

For most traits, a moderate to high heritability can be observed (Table 1) under two $\mathrm{P}$ treatments, which provides potential to improve germplasm resources by the molecular breeding method. Through forward genetics, natural variation can be mined, and superior alleles could be aggregated, which can boost breeding efficiency. In rice [20], sorghum [36], and maize [33], protein kinase PSTOL1 confers higher plant biomass and yield under P stress. Considering several key candidates related to abiotic stress and calcium-dependent protein kinase 2 identified in our GWAS results (Table 2), we believe these genes are of importance in PUE breeding. Additionally, it should be noted that one specific subpopulation harboring a relatively high percentage of a superior allele for target genes can be chosen as a donor parent to improve efficiency (Figure 7). Furthermore, whole genomic selection as a powerful tool for molecular breeding has been widely used in animal and plant breeding. The prediction abilities were illustrated for all traits in three datasets. In the low-P dataset, the prediction ability ranged from 0.15 for APUtE to 0.54 for SDWPP. For grain yield, it can still yield a prediction ability of around 0.4 . In the normal-P dataset, the prediction ability ranged from 0.10 for SePCc to 0.47 for SDWPP, while in the LPTI data the prediction ability ranged from -0.08 for ShPUtE to 0.23 for SDWPP (Figure S9). The result of the genomic selection study showed its feasibility and prospect in plant breeding, especially under $\mathrm{P}$ deficient conditions.

\section{Materials and Methods}

\subsection{Plant Materials}

A diverse GWAS population [41] was chosen and 359 lines were randomly selected for the study. It was further divided into 4 subgroups, including 28 stiff stalk lines, 113 non-stiff stalk, 111 tropical/subtropical, and 87 mixed lines [41].

\subsection{Field Design}

In May 2018, the panel was planted under the low-P and normal-P conditions in Shangzhuang Station of China Agricultural University, Beijing. P fertilizers had not been applied to the low-P field since 1985 , but $45 \mathrm{~kg} / \mathrm{ha} \mathrm{P}_{2} \mathrm{O}_{5}$ was applied before sowing for the normal-P field every year. Additionally, $240 \mathrm{~kg} / \mathrm{ha} \mathrm{N}$ fertilizer was applied in both trials before planting [79]. Based on a former study [79], for the low-P trial, the $\mathrm{N}$ and $\mathrm{K}$ concentration were $0.63-0.83 \mathrm{mg} / \mathrm{kg}$ and $109.2-147.9 \mathrm{mg} / \mathrm{kg}$, respectively; for the normal-P trial the $\mathrm{N}$ and $\mathrm{K}$ concentration were $0.69-0.77 \mathrm{mg} / \mathrm{kg}$ and $135.6-140.3 \mathrm{mg} / \mathrm{kg}$, respectively. Before sowing, the Olsen $\mathrm{P}$ in the low-P and normal-P trial were measured using a $\mathrm{NaHCO}_{3}$ method [80] by taking nine samples uniformly from the $0-20 \mathrm{~cm}$ soil; the average value 
was $2.1 \mathrm{mg} / \mathrm{kg}$ and $4.5 \mathrm{mg} / \mathrm{kg}$, respectively. The concentration of $\mathrm{P}$ was the main limiting factor. All other management measures remained the same. Each treatment was laid out as an augmented $\alpha$-design, including three replicates. Each replicate included 16 blocks, and each block contained 25 plots with the check line 'Ye478'. Each genotype was planted in a single row with a length of $1.2 \mathrm{~m}$, a plant spacing of $0.2 \mathrm{~m}$, and a row spacing of $0.5 \mathrm{~m}$. Four plants in the middle of each plot were used for phenotypic measurements.

\subsection{Acquisition of Traits}

The traits in this study mainly include two aspects: (1) the yield-related and biomassrelated traits: yield per plant (YPP), shoot dry weight per plant (SDWPP), all dry weight per plant (ADWPP); (2) PUE-related traits in seed and shoot, seed P concentration (SePCc), shoot P concentration (ShPCc), seed P content per plant (SePCPP), shoot P content per plant (ShPCPP), all P content per plant (APCPP), seed P utilization efficiency (SePUtE), shoot $P$ utilization efficiency (ShPUtE), and all P utilization efficiency (APUtE).

Seed and shoot were harvested separately in the field. The harvested seed and shoot were dried in an oven at $65^{\circ} \mathrm{C}$ to a constant weight, and weighed to calculate the dry weight per plant and the yield per plant. Then, a high-speed pulverizer was used to pulverize the seed and shoot into powder, and about $0.2 \mathrm{~g}$ of seed and about $0.4 \mathrm{~g}$ of the shoot were weighed and digested with $\mathrm{H}_{2} \mathrm{SO}_{4}$ and $\mathrm{H}_{2} \mathrm{O}_{2}$ until the liquid was transparent. Then, the $\mathrm{P}$ concentration was measured following the spectrophotometric method.

$\mathrm{P}$ content is equal to the product of $\mathrm{P}$ concentration and dry weight, calculated in shoot and seed respectively; all P content per plant was calculated as APCPP $=$ SePCPP + ShPCPP [38]. PUtE is equal to the inverse of P concentration [81], meaning the yield or dry matter mass produced by absorbing $1 \mathrm{mg}$ of $\mathrm{P}$, which represents the utilization efficiency of the phosphorus absorbed by the plant. The LPTI was calculated by the performance under low-P divided by the trait performance under normal-P, and was used as an index for GWAS. The descriptions of all traits used in this study are listed in Table S3.

\subsection{Phenotypic Data Analysis}

First of all, the method of Studentized Residual Razor was used to remove outliers in the original data, with a threshold of 2.8 [82]. The best linear unbiased estimator (BLUE) value of each trait under low-P and normal-P conditions were calculated with the following formula:

$$
y=\mu+G+\operatorname{Rep}+\operatorname{Block}(\operatorname{Rep})+\varepsilon,
$$

where $y$ represented the phenotype observation value; $\mu$ was the overall mean; $G$ was the genotypic effect; Rep was the effect of replication; Block(Rep) was the block effect nested within the replication; $\varepsilon$ was the error, and $\varepsilon$ was subject to follow a normal distribution in each replication; $G$ was a fixed effect; and the rest were random effects.

For the analysis of genetic variance and interaction variance across the two P conditions, the model was:

$$
y=\mu+G+T+G^{*} T+\operatorname{Rep}(T)+\operatorname{Block}(\operatorname{Rep})+\varepsilon,
$$

where $y, \mu, G, B \operatorname{lock}(\operatorname{Rep})$ was the same as the above model; $T$ was the effect of treatment with two P conditions; $G^{*} T$ was the interaction of the genotype-by-P treatment; and $\operatorname{Rep}(T)$ was the replication effect in each treatment, assuming that $\varepsilon$ followed a normal distribution within each $P$ treatment. Except for the $T$ effect, the others were treated as random effects. The method of Cullis was used to calculate the repeatability under each P treatment and the heritability across treatments with the following formula [83]:

$$
H^{2}=1-\frac{\bar{v}_{\text {BLUP }}}{2 \sigma_{G}^{2}}
$$

where $\bar{v}_{\text {BLUP }}$ was the mean variance of a difference of two BLUP, and $\sigma_{G}^{2}$ was the genetic variance estimated by REML in the R package 'sommer' (version 4.1.3) [84]. 


\subsection{Genome-Wide Association Study}

By integrating RNA-Seq data of 368 inbred lines and Illumina SNP50 Bead Chip genotype data of 513 inbred lines, 556,809 high-quality SNP data were obtained [85], publicly available at http:/ / www.maizego.org/Resources.html (accessed on 9 June 2021). The reference genome in this study was B73 RefGen_v3. Based on the original 513 lines, the genotypes of 359 individuals were extracted and filtered according to the missing rate lower than 0.2 and the minor allele frequency greater than 0.05 , and finally, 534,772 SNP markers remained. The Bayesian-information and Linkage-disequilibrium Iteratively Nested Keyway model, in which pseudo QTNs were used to control false positives and reduce false negatives [86], was used to implement a GWAS in GAPIT (version 3) [87]. Since redundant markers are in strong linkage disequilibrium, it was too strict to calculate the Bonferroni-corrected threshold using all markers. Therefore, we used the indep-pairwise module of PLINK (http://pngu.mgh.harvard.edu/purcell/plink/, version 1.9) [88] to calculate the independent marker numbers, with the parameters window size equal to 50 , step size equal to 50, and $r^{2}$ greater than or equal to 0.2 [89]; finally, 87,096 independent markers were obtained. The suggestive threshold to control the type I error rate was global $\alpha=0.10$, thus the significant threshold was $-\log _{10}(0.10 /(87,096 / 10))=4.94$ with chromosome-wide Bonferroni correction.

Candidate genes were identified when the significant SNPs were in genes or genes were within a $5 \mathrm{~kb}$ distance from the significant SNPs. Gene annotations were downloaded from maizeGDB (https:/ / www.maizegdb.org/, accessed on 9 June 2021). For the key genes without annotations, BLASTP was conducted in Tbtools (version 1.075) [90] to get the best hit genes in Arabidopsis. One or two genes with the smallest e-value were taken as the homologous genes, and annotations were downloaded from TAIR (https: / / www.arabidopsis.org/, accessed on 9 June 2021).

\subsection{Gene Ontology Analysis}

To further understand the metabolic pathways of candidate genes, we conducted GO analysis for genes identified in GWAS in the low-P condition with a threshold of 4.0, which was slightly lower than the threshold of independent GWAS. The moderate threshold was used to balance the false positives and false negatives for the entries of GO analysis, which included another significance test to promise low false positives. This process was implemented using agriGO v2.0 (http:/ / systemsbiology.cau.edu.cn/, version 2.0, accessed on 9 June 2021) [91].

\subsection{Phylogenetic Characterization and Conserved Motif Analysis}

To find out the conserved motifs of the PHT1 family among different plant species, the protein sequence of PHT1 in maize was used as a query sequence for BLAST. We identified PHT1 homologous genes in four species, namely maize (Zea mays L.), Arabidopsis (Arabidopsis thaliana L.), rice (Oryza sativa L.), and sorghum (Sorghum bicolor L.). Corresponding gene annotations were obtained from the maizeGDB, TAIR, China Rice Data Center (http:/ /www.ricedata.cn/gene/, accessed on 9 June 2021), and NCBI (https: / / www.ncbi.nlm.nih.gov/, accessed on 9 June 2021), respectively. One sorghum gene did not contain the PHT1 specific signature (GGDYPLSATIxSE) [74]. Then, protein sequences were downloaded from EnsemblPlants (http:/ / plants.ensembl.org/, accessed on 9 June 2021). A phylogenetic tree was generated by mega7.0 [92] software, and motif analysis was completed with MEME by setting the maximum number of motifs to 10 (https: //meme-suite.org/meme/, accessed on 9 June 2021). The DNA sequences $1 \mathrm{~kb}$ upstream of the transcriptional start site of the first transcript were extracted in TBtools and were submitted to PlantCARE (http:/ / bioinformatics.psb.ugent.be/webtools/plantcare/html/, accessed on 9 June 2021) for prediction of cis-elements. Finally, the TBtools were used to repaint the results with default parameters. 


\subsection{Haplotype Identification}

To further understand the differences between the haplotypes of target genes, and illustrate the percentage of favorable haplotypes among different subpopulations (SS, NSS, TST, and mixed), five genes, namely GRMZM2G326707, GRMZM5G848945, GRMZM2G381709, GRMZM2G088487, and GRMZM2G054050, closely related to P stress from both the results of GWAS in this study and previous studies [53], were taken as examples. Firstly, the SNPs located in the gene were chosen, then Tag SNPs were identified by setting $r^{2}$ equal to 0.8 and the others as default in HaploView (version 4.2.) [93] Afterward, Tag SNPs were used to make up haplotypes among the population. To ensure the accuracy of statistics, we removed individuals and genotypes with missing phenotypes, and only major haplotypes (frequency $>0.05$ ) were kept. Among these haplotypes, the one with the highest average effect was regarded as the favorable haplotype, and the others were classified as remaining haplotypes.

\subsection{Genomic Selection}

The genomic best linear unbiased prediction model [94] was implemented in R (version 4.0.3) package rrBLUP (version 4.6.1) [95] for genomic selection. The prediction ability was evaluated by the correlation between the actual values and predicted values. Five-fold cross-validation with 1000 repetitions was used to yield the final accuracy.

Supplementary Materials: The following are available online at https:/ /www.mdpi.com/article/10 .3390/ijms22179311/s1.

Author Contributions: Conceptualization, W.L., T.W., L.Y., F.C. and S.C.; methodology, W.L. and T.W.; software, D.L., H.W., M.W. (Meng Wang) and G.L.; validation, D.L. and H.W.; formal analysis, D.L., H.W. and M.W. (Meng Wang); investigation, D.L., H.W., M.W. (Meng Wang), Z.C., X.L. and M.W. (Ming Wang); resources, W.L.; data curation, W.L. and D.L.; writing-original draft preparation, D.L., H.W. and W.L.; writing - review and editing, D.L., H.W., W.L., W.L.L., T.M.W. and T.W.; visualization, D.L. and H.W.; supervision, W.L.; project administration, W.L.; funding acquisition, W.L. and S.C. All authors have read and agreed to the published version of the manuscript.

Funding: This research was funded by the National Key Research and Development Program of China, grant number 2016YFD0101201 and 2018YFD0100201, and funded by the Deutsche Forschungsgemeinschaft (DFG, German Research Foundation)—328017493/GRK 2366 (Sino-German International Research Training Group AMAIZE-P).

Data Availability Statement: All relevant data are within the paper and its Supplementary Materials.

Acknowledgments: We thank Jianbing Yan at Huazhong Agricultural University and Xiaohong Yang at China Agricultural University for providing materials in our experiment. We also thank Junjie Fu at Chinese Academy of Agricultural Sciences for suggestions on revisions. We sincerely thank the editors and anonymous reviewers for their constructive comments and suggestions on the manuscript.

Conflicts of Interest: The authors declare no conflict of interest.

\section{References}

1. Wissuwa, M. How do Plants Achieve Tolerance to Phosphorus Deficiency? Small Causes with Big Effects. Plant. Physiol. 2003, 133, 1947-1958. [CrossRef]

2. Heuer, S.; Gaxiola, R.; Schilling, R.; Herrera-Estrella, L.; López-Arredondo, D.; Wissuwa, M.; Delhaize, E.; Rouached, H. Improving Phosphorus Use Efficiency: A Complex Trait with Emerging Opportunities. Plant. J. 2017, 90, 868-885. [CrossRef] [PubMed]

3. Kochian, L.V. Plant Nutrition: Rooting for More Phosphorus. Nature 2012, 488, 466-467. [CrossRef]

4. Chen, M.P.; Graedel, T.E. A Half-Century of Global Phosphorus Flows, Stocks, Production, Consumption, Recycling, and Environmental Impacts. Glob. Environ. Chang. 2016, 36, 139-152. [CrossRef]

5. Cordell, D.; Drangert, J.O.; White, S. The Story of Phosphorus: Global Food Security and Food for Thought. Glob. Environ. Chang. 2009, 19, 292-305. [CrossRef]

6. Desmidt, E.; Ghyselbrecht, K.; Zhang, Y.; Pinoy, L.; Van Der Bruggen, B.; Verstraete, W.; Rabaey, K.; Meesschaert, B. Global Phosphorus Scarcity and Full-Scale P-Recovery Techniques: A Review. Crit. Rev. Environ. Sci. Technol. 2015, 45, 336-384. [CrossRef] 
7. Teng, W.; He, X.; Tong, Y.P. Transgenic Approaches for Improving Use Efficiency of Nitrogen, Phosphorus and Potassium in Crops. J. Integr. Agric. 2017, 16, 2657-2673. [CrossRef]

8. Vance, C.P.; Uhde-Stone, C.; Allan, D.L. Phosphorus Acquisition and Use: Critical Adaptations by Plants for Securing a Nonrenewable Resource. New Phytol. 2003, 157, 423-447. [CrossRef] [PubMed]

9. Hsieh, L.C.; Lin, S.I.; Shih, A.C.C.; Chen, J.W.; Lin, W.Y.; Tseng, C.Y.; Li, W.H.; Chiou, T.J. Uncovering Small RNA-Mediated Responses to Phosphate Deficiency in Arabidopsis by Deep Sequencing. Plant. Physiol. 2009, 151, 2120-2132. [CrossRef] [PubMed]

10. Khan, G.A.; Vogiatzaki, E.; Glauser, G.; Poirier, Y. Phosphate Deficiency Induces the Jasmonate Pathway and Enhances Resistance to Insect Herbivory. Plant. Physiol. 2016, 171, 632-644. [CrossRef] [PubMed]

11. Li, K.P.; Xu, C.Z.; Li, Z.X.; Zhang, K.W.; Yang, A.F.; Zhang, J.R. Comparative Proteome Analyses of Phosphorus Responses in Maize (Zea Mays L.) Roots of Wild-Type and a Low-P-Tolerant Mutant Reveal Root Characteristics Associated with Phosphorus Efficiency. Plant. J. 2008, 55, 927-939. [CrossRef]

12. Mori, A.; Fukuda, T.; Vejchasarn, P.; Nestler, J.; Pariasca-Tanaka, J.; Wissuwa, M. The Role of Root Size versus Root Efficiency in Phosphorus Acquisition in Rice. J. Exp. Bot. 2016, 67, 1179-1189. [CrossRef] [PubMed]

13. Vejchasarn, P.; Lynch, J.P.; Brown, K.M. Genetic Variability in Phosphorus Responses of Rice Root Phenotypes. Rice 2016, 9, 1-16. [CrossRef]

14. Zhang, H.W.; Xu, R.N.; Xi, C.X.; Huang, C.L.; Liao, H.; Xu, Y.B.; Wang, J.X.; Li, W.X. Large-Scale Evaluation of Maize Germplasm for Low-Phosphorus Tolerance. PLoS ONE 2015, 10, e0124212.

15. Li, D.D.; Wang, M.; Kuang, X.Y.; Liu, W.X. Genetic Study and Molecular Breeding for High Phosphorus Use Efficiency in Maize. Front. Agric. Sci. Eng. 2019, 6, 366-379. [CrossRef]

16. Nagy, R.; Vasconcelos, M.J.V.; Zhao, S.; McElver, J.; Bruce, W.; Amrhein, N.; Raghothama, K.G.; Bucher, M. Differential Regulation of Five Pht1 Phosphate Transporters from Maize (Zea Mays L.). Plant. Biol. 2006, 8, 186-197. [CrossRef]

17. Huang, K.L.; Ma, G.J.; Zhang, M.L.; Xiong, H.; Wu, H.; Zhao, C.Z.; Liu, C.-S.; Jia, H.X.; Chen, L.; Kjorven, J.O.; et al. The ARF7 and ARF19 Transcription Factors Positively Regulate PHOSPHATE STARVATION RESPONSE1 in Arabidopsis Roots. Plant. Physiol. 2018, 178, 413-427. [CrossRef] [PubMed]

18. Pant, B.D.; Burgos, A.; Pant, P.; Cuadros-Inostroza, A.; Willmitzer, L.; Scheible, W.R. The Transcription Factor PHR1 Regulates Lipid Remodeling and Triacylglycerol Accumulation in Arabidopsis Thaliana during Phosphorus Starvation. J. Exp. Bot. 2015, 66, 1907-1918. [CrossRef]

19. Devaiah, B.N.; Nagarajan, V.K.; Raghothama, K.G. Phosphate Homeostasis and Root Development in Arabidopsis Are Synchronized by the Zinc Finger Transcription Factor ZAT6. Plant. Physiol. 2007, 145, 147-159. [CrossRef]

20. Gamuyao, R.; Chin, J.H.; Pariasca-Tanaka, J.; Pesaresi, P.; Catausan, S.; Dalid, C.; Slamet-Loedin, I.; Tecson-Mendoza, E.M.; Wissuwa, M.; Heuer, S. The Protein Kinase Pstol1 from Traditional Rice Confers Tolerance of Phosphorus Deficiency. Nature 2012, 488, 535-539. [CrossRef]

21. Chandrika, N.N.P.; Sundaravelpandian, K.; Yu, S.M.; Schmidt, W. ALFIN-LIKE 6 Is Involved in Root Hair Elongation during Phosphate Deficiency in Arabidopsis. New Phytol. 2013, 198, 709-720. [CrossRef] [PubMed]

22. Chen, Z.H.; Nimmo, G.A.; Jenkins, G.I.; Nimmo, H.G. BHLH32 Modulates Several Biochemical and Morphological Processes That Respond to Pi Starvation in Arabidopsis. Biochem. J. 2007, 405, 191-198. [CrossRef]

23. Chen, Z.H.; Jenkins, G.I.; Nimmo, H.G. Identification of an F-Box Protein That Negatively Regulates Pi Starvation Responses Plant. Cell Physiol. 2008, 49, 1902-1906. [CrossRef] [PubMed]

24. Zhang, Z.M.; Lin, H.J.; Shen, Y.O.; Gao, J.; Xiang, K.; Liu, L.; Ding, H.P.; Yuan, G.S.; Lan, H.; Zhou, S.F.; et al. Cloning and Characterization of MiRNAs from Maize Seedling Roots under Low Phosphorus Stress. Mol. Biol. Rep. 2012, 39, 8137-8146. [CrossRef] [PubMed]

25. Hasan, M.M.; Hasan, M.M.; Teixeira da Silva, J.A.; Li, X.X. Regulation of Phosphorus Uptake and Utilization: Transitioning from Current Knowledge to Practical Strategies. Cell. Mol. Biol. Lett. 2016, 21, 1-19. [CrossRef] [PubMed]

26. Du, Q.G.; Wang, K.; Zou, C.; Xu, C.; Li, W.X. The PILNCR1-MiR399 Regulatory Module is Important for Low Phosphate Tolerance in Maize. Plant. Physiol. 2018, 177, 1743-1753. [CrossRef] [PubMed]

27. Wang, X.; Wang, H.F.; Chen, Y.; Sun, M.M.; Wang, Y.; Chen, Y.F. The Transcription Factor NIGT1.2 Modulates Both Phosphate Uptake and Nitrate Influx during Phosphate Starvation in Arabidopsis and Maize. Plant. Cell 2020, 32, 3519-3534. [CrossRef]

28. Wang, X.H.; Bai, J.R.; Liu, H.M.; Sun, Y.; Shi, X.Y.; Ren, Z.Q. Overexpression of a Maize Transcription Factor ZmPHR1 Improves Shoot Inorganic Phosphate Content and Growth of Arabidopsis under Low-Phosphate Conditions. Plant. Mol. Biol. Rep. 2013, 31, 665-677. [CrossRef]

29. Maharajan, T.; Ceasar, S.A.; Ajeesh krishna, T.P.; Ramakrishnan, M.; Duraipandiyan, V.; Naif Abdulla, A.D.; Ignacimuthu, S. Utilization of Molecular Markers for Improving the Phosphorus Efficiency in Crop Plants. Plant. Breed. 2017, 137, 1-17. [CrossRef]

30. Zhu, J.M.; Mickelson, S.M.; Kaeppler, S.M.; Lynch, J.P. Detection of Quantitative Trait Loci for Seminal Root Traits in Maize (Zea Mays L.) Seedlings Grown under Differential Phosphorus Levels. Theor. Appl. Genet. 2006, 113, 1-10.

31. Wang, Q.J.; Yuan, Y.B.; Liao, Z.Q.; Jiang, Y.; Wang, Q.; Zhang, L.T.; Gao, S.B.; Wu, F.K.; Li, M.L.; Xie, W.B.; et al. Genome-Wide Association Study of 13 Traits in Maize Seedlings under Low Phosphorus Stress. Plant. Genome 2019, 12, 1-13. [CrossRef] [PubMed]

32. Neelam, K.; Thakur, S.; Neha; Yadav, I.S.; Kumar, K.; Dhaliwal, S.S.; Singh, K. Novel Alleles of Phosphorus-Starvation Tolerance 1 Gene (PSTOL1) from Oryza Rufipogon Confers High Phosphorus Uptake Efficiency. Front. Plant. Sci. 2017, 8, 1-12. [CrossRef] 
33. Azevedo, G.C.; Cheavegatti-Gianotto, A.; Negri, B.F.; Hufnagel, B.; e Silva, L.D.C.; Magalhaes, J.V.; Garcia, A.A.F.; Lana, U.G.P.; de Sousa, S.M.; Guimaraes, C.T. Multiple Interval QTL Mapping and Searching for PSTOL1 Homologs Associated with Root Morphology, Biomass Accumulation and Phosphorus Content in Maize Seedlings under Low-P. BMC Plant. Biol. 2015, 15, 1-17. [CrossRef] [PubMed]

34. Zhang, G.D.; Wang, X.P.; Wang, B.; Tian, Y.C.; Li, M.; Nie, Y.X.; Peng, Q.C.; Wang, Z.L. Fine Mapping a Major QTL for Kernel Number per Row under Different Phosphorus Regimes in Maize (Zea Mays L.). Theor. Appl. Genet. 2013, 126, $1545-1553$. [CrossRef] [PubMed]

35. Xu, C.; Zhang, H.W.; Sun, J.H.; Guo, Z.F.; Zou, C.; Li, W.X.; Xie, C.X.; Huang, C.L.; Xu, R.N.; Liao, H.; et al. Genome-Wide Association Study Dissects Yield Components Associated with Low-Phosphorus Stress Tolerance in Maize. Theor. Appl. Genet. 2018, 131, 1699-1714. [CrossRef] [PubMed]

36. Hufnagel, B.; de Sousa, S.M.; Assis, L.; Guimaraes, C.T.; Leiser, W.; Azevedo, G.C.; Negri, B.; Larson, B.G.; Shaff, J.E.; Pastina, M.M.; et al. Duplicate and Conquer: Multiple Homologs of PHOSPHORUS-STARVATION TOLERANCE1 Enhance Phosphorus Acquisition and Sorghum Performance on Low-Phosphorus Soils. Plant. Physiol. 2014, 166, 659-677. [CrossRef] [PubMed]

37. Qiu, H.B.; Mei, X.P.; Liu, C.X.; Wang, J.G.; Wang, G.Q.; Wang, X.; Liu, Z.; Cai, Y.L. Fine Mapping of Quantitative Trait Loci for Acid Phosphatase Activity in Maize Leaf under Low Phosphorus Stress. Mol. Breed. 2013, 32, 629-639. [CrossRef]

38. Mendes, F.F.; Guimarães, L.J.M.; Souza, J.C.; Guimarães, P.E.O.; Magalhaes, J.V.; Garcia, A.A.F.; Parentoni, S.N.; Guimaraes, C.T. Genetic Architecture of Phosphorus Use Efficiency in Tropical Maize Cultivated in a Low-P Soil. Crop. Sci. 2014, 54, 1530-1538. [CrossRef]

39. Xiao, Y.J.; Liu, H.J.; Wu, L.J.; Warburton, M.; Yan, J.B. Genome-Wide Association Studies in Maize: Praise and Stargaze. Mol. Plant. 2017, 10, 359-374. [CrossRef]

40. Luo, B.W.; Ma, P.; Nie, Z.; Zhang, X.; He, X.; Ding, X.; Feng, X.; Lu, Q.X.; Ren, Z.Y.; Lin, H.J.; et al. Metabolite Profiling and Genome-Wide Association Studies Reveal Response Mechanisms of Phosphorus Deficiency in Maize Seedling. Plant. J. 2019, 97, 947-969. [CrossRef]

41. Yang, X.H.; Gao, S.B.; Xu, S.T.; Zhang, Z.X.; Prasanna, B.M.; Li, L.; Li, J.S.; Yan, J.B. Characterization of a Global Germplasm Collection and Its Potential Utilization for Analysis of Complex Quantitative Traits in Maize. Mol. Breed. 2011, 28, 511-526. [CrossRef]

42. Sun, Y.L.; Mu, C.H.; Liu, X. Key Factors Identified by Proteomic Analysis in Maize (Zea Mays L.) Seedlings' Response to Long-Term Exposure to Different Phosphate Levels. Proteome Sci. 2018, 16, 1-17. [CrossRef]

43. Shen, J.B.; Yuan, L.X.; Zhang, J.L.; Li, H.G.; Bai, Z.H.; Chen, X.P.; Zhang, W.F.; Zhang, F.S. Phosphorus Dynamics: From Soil to Plant. Plant. Physiol. 2011, 156, 997-1005. [CrossRef] [PubMed]

44. He, C.M.; Liu, H.L.; Su, S.Z.; Lu, Y.L.; Luo, B.W.; Nie, Z.; Wu, L.; Liu, D.; Zhang, X.; Rong, T.Z.; et al. Genome-Wide Identification of Candidate Phosphate Starvation Responsive Genes and the Development of Intron Length Polymorphism Markers in Maize. Plant. Breed. 2015, 134, 11-16. [CrossRef]

45. Baek, D.; Park, H.C.; Kim, M.C.; Yun, D.J. The Role of Arabidopsis MYB2 in MiR399f-Mediated Phosphate-Starvation Response. Plant. Signal. Behav. 2013, 8, 8-10. [CrossRef] [PubMed]

46. Mao, C.J.; He, J.M.; Liu, L.N.; Deng, Q.M.; Yao, X.F.; Liu, C.M.; Qiao, Y.L.; Li, P.; Ming, F. OsNAC2 Integrates Auxin and Cytokinin Pathways to Modulate Rice Root Development. Plant. Biotechnol. J. 2020, 18, 429-442. [CrossRef]

47. Wang, M.; Qiao, J.Y.; Yu, C.L.; Chen, H.; Sun, C.D.; Huang, L.Z.; Li, C.Y.; Geisler, M.; Qian, Q.; Jiang, D.A.; et al. The Auxin Influx Carrier, OsAUX3, Regulates Rice Root Development and Responses to Aluminium Stress. Plant. Cell Environ. 2019, 42, 1125-1138. [CrossRef]

48. Yu, C.; Yan, M.; Dong, H.; Luo, J.; Ke, Y.; Guo, A.; Chen, Y.; Zhang, J.; Huang, X. Maize BHLH55 Functions Positively in Salt Tolerance through Modulation of AsA Biosynthesis by Directly Regulating GDP-Mannose Pathway Genes. Plant. Sci. 2021, 302, 110676. [CrossRef]

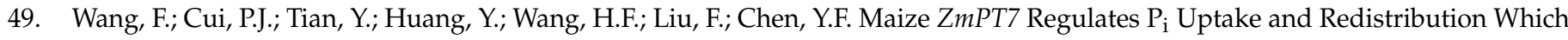
is Modulated by Phosphorylation. Plant. Biotechnol. J. 2020, 18, 2406-2419. [CrossRef]

50. Bari, R.; Pant, B.D.; Stitt, M. PHO2, MicroRNA399, and PHR1 Define APhosphate-Signaling Pathway in Plants. Society 2006, 141, 988-999.

51. Smith, A.P.; Jain, A.; Deal, R.B.; Nagarajan, V.K.; Poling, M.D.; Raghothama, K.G.; Meagher, R.B. Histone H2A.Z Regulates the Expression of Several Classes of Phosphate Starvation Response Genes but Not as a Transcriptional Activator. Plant. Physiol. 2010, 152, 217-225. [CrossRef] [PubMed]

52. Svistoonoff, S.; Creff, A.; Reymond, M.; Sigoillot-Claude, C.; Ricaud, L.; Blanchet, A.; Nussaume, L.; Desnos, T. Root Tip Contact with Low-Phosphate Media Reprograms Plant Root Architecture. Nat. Genet. 2007, 39, 792-796. [CrossRef] [PubMed]

53. Calderón-Vázquez, C.; Sawers, R.J.H.; Herrera-Estrella, L. Phosphate Deprivation in Maize: Genetics and Genomics. Plant. Physiol. 2011, 156, 1067-1077. [CrossRef] [PubMed]

54. Cai, H.G.; Chu, Q.; Yuan, L.X.; Liu, J.C.; Chen, X.H.; Chen, F.J.; Mi, G.H.; Zhang, F.S. Identification of Quantitative Trait Loci for Leaf Area and Chlorophyll Content in Maize (Zea Mays) under Low Nitrogen and Low Phosphorus Supply. Mol. Breed. 2012, 30 , 251-266. [CrossRef]

55. Chen, S.S.; Ding, G.D.; Wang, Z.H.; Cai, H.M.; Xu, F.S. Proteomic and Comparative Genomic Analysis Reveals Adaptability of Brassica Napus to Phosphorus-Deficient Stress. J. Proteom. 2015, 117, 106-119. [CrossRef] 
56. Yao, Q.L.; Yang, K.C.; Pan, G.T.; Rong, T.Z. The Effects of Low Phosphorus Stress on Morphological and Physiological Characteristics of Maize (Zea Mays L.) Landraces. Agric. Sci. China 2007, 6, 559-566. [CrossRef]

57. Li, H.; Peng, Z.Y.; Yang, X.H.; Wang, W.D.; Fu, J.J.; Wang, J.H.; Han, Y.J.; Chai, Y.C.; Guo, T.T.; Yang, N.; et al. Genome-Wide Association Study Dissects the Genetic Architecture of Oil Biosynthesis in Maize Kernels. Nat. Genet. 2013, 45, 43-50. [CrossRef]

58. Xia, K.F.; Wang, R.; Ou, X.J.; Fang, Z.M.; Tian, C.E.; Duan, J.; Wang, Y.Q.; Zhang, M.Y. OsTIR1 and OsAFB2 Downregulation via OsmiR393 Overexpression Leads to More Tillers, Early Flowering and Less Tolerance to Salt and Drought in Rice. PLoS ONE 2012, 7, e30039.

59. Shriram, V.; Kumar, V.; Devarumath, R.M.; Khare, T.S.; Wani, S.H. MicroRNAs as Potential Targets for Abiotic Stress Tolerance in Plants. Front. Plant. Sci. 2016, 7, 1-18. [CrossRef]

60. Buck, M.J.; Atchley, W.R. Phylogenetic Analysis of Plant Basic Helix-Loop-Helix Proteins. J. Mol. Evol. 2003, 56, 742-750. [CrossRef]

61. Li, Z.X.; Liu, C.; Zhang, Y.; Wang, B.M.; Ran, Q.J.; Zhang, J.R. The BHLH Family Member ZmPTF1 Regulates Drought Tolerance in Maize by Promoting Root Development and Abscisic Acid Synthesis. J. Exp. Bot. 2019, 70, 5471-5486. [CrossRef]

62. Castilhos, G.; Lazzarotto, F.; Spagnolo-Fonini, L.; Bodanese-Zanettini, M.H.; Margis-Pinheiro, M. Possible Roles of Basic HelixLoop-Helix Transcription Factors in Adaptation to Drought. Plant. Sci. 2014, 223, 1-7. [CrossRef] [PubMed]

63. Babiychuk, E.; Müller, F.; Eubel, H.; Braun, H.P.; Frentzen, M.; Kushnir, S. Arabidopsis Phosphatidylglycerophosphate Synthase 1 Is Essential for Chloroplast Differentiation, but is Dispensable for Mitochondrial Function. Plant. J. 2003, 33, 899-909. [CrossRef]

64. Xu, C.C.; Härtel, H.; Wada, H.; Hagio, M.; Yu, B.; Eakin, C.; Benning, C. The Pgp1 Mutant Locus of Arabidopsis Encodes a Phosphatidylglycerolphosphate Synthase with Impaired Activity. Plant. Physiol. 2002, 129, 594-604. [CrossRef]

65. Thole, J.M.; Vermeer, J.E.M.; Zhang, Y.L.; Gadella, T.W.J.; Nielsen, E. Root Hair Defective4 Encodes a Phosphatidylinositol-4Phosphate Phosphatase Required for Proper Root Hair Development in Arabidopsis Thaliana. Plant. Cell 2008, 20, $381-395$. [CrossRef]

66. Yang, M.; Ding, G.D.; Shi, L.; Feng, J.; Xu, F.S.; Meng, J.L. Quantitative Trait Loci for Root Morphology in Response to Low Phosphorus Stress in Brassica Napus. Theor. Appl. Genet. 2010, 121, 181-193. [CrossRef] [PubMed]

67. Lee, J.E.; Lampugnani, E.R.; Bacic, A.; Golz, J.F. SEUSS and SEUSS-LIKE 2 Coordinate Auxin Distribution and KNOXI Activity during Embryogenesis. Plant. J. 2014, 80, 1-32. [CrossRef]

68. Shrestha, B.; Guragain, B.; Sridhar, V.V. Involvement of Co-Repressor LUH and the Adapter Proteins SLK1 and SLK2 in the Regulation of Abiotic Stress Response Genes in Arabidopsis. BMC Plant. Biol. 2014, 14, 1-14. [CrossRef] [PubMed]

69. Amini, S.; Goh, H.H.; Wan, K.L. Identification of Calcium-Dependent Protein Kinase (CDPK): A Multi-Functional Gene Family in Rafflesia Cantleyi. AIP Conf. Proc. 2016, 1784, 020003.

70. Cheng, S.H.; Willmann, M.R.; Chen, H.C.; Sheen, J. Calcium Signaling through Protein Kinases. The Arabidopsis CalciumDependent Protein Kinase Gene Family. Plant. Physiol. 2002, 129, 469-485. [CrossRef]

71. Coelho, G.T.C.P.; Carneiro, N.P.; Karthikeyan, A.S.; Raghothama, K.G.; Schaffert, R.E.; Brandão, R.L.; Paiva, L.V.; Souza, I.R.P.; Alves, V.M.; Imolesi, A.; et al. A Phosphate Transporter Promoter from Arabidopsis Thaliana AtPHT1;4 Gene Drives Preferential Gene Expression in Transgenic Maize Roots under Phosphorus Starvation. Plant. Mol. Biol. Rep. 2010, 28, 717-723. [CrossRef]

72. Smith, F.W.; Mudge, S.R.; Rae, A.L.; Glassop, D. Phosphate Transport in Plants. Plant. Soil 2003, 248, 71-83. [CrossRef]

73. Ye, Y.; Yuan, J.; Chang, X.J.; Yang, M.; Zhang, L.J.; Lu, K.; Lian, X.M. The Phosphate Transporter Gene OsPht1;4 is Involved in Phosphate Homeostasis in Rice. PLoS ONE 2015, 10, e0126186. [CrossRef]

74. Walder, F.; Brulé, D.; Koegel, S.; Wiemken, A.; Boller, T.; Courty, P.E. Plant Phosphorus Acquisition in a Common Mycorrhizal Network: Regulation of Phosphate Transporter Genes of the Pht1 Family in Sorghum and Flax. New Phytol. 2015, 205, 1632-1645. [CrossRef]

75. Ayadi, A.; David, P.; Arrighi, J.F.; Chiarenza, S.; Thibaud, M.C.; Nussaume, L.; Marin, E. Reducing the Genetic Redundancy of Arabidopsis Phosphate Transporter1 Transporters to Study Phosphate Uptake and Signaling. Plant. Physiol. 2015, 167, 1511-1526. [CrossRef]

76. Zhang, Z.; Zhang, J.; Chen, Y.; Li, R.; Wang, H.; Wei, J. Genome-Wide Analysis and Identification of HAK Potassium Transporter Gene Family in Maize (Zea Mays L.). Mol. Biol. Rep. 2012, 39, 8465-8473. [CrossRef]

77. Zhong, Y.T.; Pan, X.Y.; Wang, R.F.; Xu, J.L.; Guo, J.Y.; Yang, T.X.; Zhao, J.Y.; Nadeem, F.; Liu, X.T.; Shan, H.Y.; et al. ZmCCD10a Encodes a Distinct Type of Carotenoid Cleavage Dioxygenase and Enhances Plant Tolerance to Low Phosphate. Plant. Physiol. 2020, 184, 374-392. [CrossRef]

78. Wang, R.F.; Zhong, Y.T.; Liu, X.T.; Zhao, C.; Zhao, J.Y.; Li, M.F.; Ul Hassan, M.; Yang, B.; Li, D.D.; Liu, R.Y.; et al. Cis-Regulation of the Amino Acid Transporter Genes ZmAAP2 and ZmLHT1 by ZmPHR1 Transcription Factors in Maize Ear under Phosphate Limitation. J. Exp. Bot. 2021, 72, 3846-3863. [CrossRef]

79. Gu, R.L.; Chen, F.J.; Long, L.Z.; Cai, H.G.; Liu, Z.G.; Yang, J.B.; Wang, L.F.; Li, H.Y.; Li, J.H.; Liu, W.X.; et al. Enhancing Phosphorus Uptake Efficiency through QTL-Based Selection for Root System Architecture in Maize. J. Genet. Genom. 2016, 43, 663-672. [CrossRef]

80. Olsen, S.R.; Cole, C.V.; Watanabe, F.S.; Dean, L.A. Estimation of Available Phosphorus in Soils by Extraction with Sodium Bicarbonate; United States Department of Agriculture: Washington, DC, USA, 1954; pp. 1-19.

81. Ludewig, U.; Yuan, L.X.; Neumann, G. Improving the Efficiency and Effectiveness of Global Phosphorus Use: Focus on Root and Rhizosphere Levels in the Agronomic System. Front. Agric. Sci. Eng. 2019, 6, 357-365. [CrossRef] 
82. Bernal-Vasquez, A.M.; Utz, H.F.; Piepho, H.P. Outlier Detection Methods for Generalized Lattices: A Case Study on the Transition from ANOVA to REML. Theor. Appl. Genet. 2016, 129, 787-804. [CrossRef]

83. Cullis, B.R.; Smith, A.B.; Coombes, N.E. On the Design of Early Generation Variety Trials with Correlated Data. J. Agric. Biol. Environ. Stat. 2006, 11, 381-393. [CrossRef]

84. Covarrubias-Pazaran, G. Genome-Assisted Prediction of Quantitative Traits Using the r Package Sommer. PLoS ONE 2016, 11, e0156744. [CrossRef] [PubMed]

85. Yang, N.; Lu, Y.L.; Yang, X.H.; Huang, J.; Zhou, Y.; Ali, F.; Wen, W.W.; Liu, J.; Li, J.S.; Yan, J.B. Genome Wide Association Studies Using a New Nonparametric Model Reveal the Genetic Architecture of 17 Agronomic Traits in an Enlarged Maize Association Panel. PLoS Genet. 2014, 10, e1004573. [CrossRef]

86. Cui, Z.H.; Dong, H.X.; Zhang, A.; Ruan, Y.Y.; Jiang, S.Q.; He, Y.; Zhang, Z.W. Denser Markers and Advanced Statistical Method Identified More Genetic Loci Associated with Husk Traits in Maize. Sci. Rep. 2020, 10, 1-10. [CrossRef]

87. Lipka, A.E.; Tian, F.; Wang, Q.S.; Peiffer, J.; Li, M.; Bradbury, P.J.; Gore, M.A.; Buckler, E.S.; Zhang, Z.W. GAPIT: Genome Association and Prediction Integrated Tool. Bioinformatics 2012, 28, 2397-2399. [CrossRef]

88. Purcell, S.; Neale, B.; Todd-Brown, K.; Thomas, L.; Ferreira, M.A.R.; Bender, D.; Maller, J.; Sklar, P.; De Bakker, P.I.W.; Daly, M.J.; et al. PLINK: A Tool Set for Whole-Genome Association and Population-Based Linkage Analyses. Am. J. Hum. Genet. 2007, 81, 559-575. [CrossRef]

89. Wang, X.L.; Wang, H.W.; Liu, S.X.; Ferjani, A.; Li, J.S.; Yan, J.B.; Yang, X.H.; Qin, F. Genetic Variation in ZmVPP1 Contributes to Drought Tolerance in Maize Seedlings. Nat. Genet. 2016, 48, 1233-1241. [CrossRef] [PubMed]

90. Chen, C.J.; Chen, H.; Zhang, Y.; Thomas, H.R.; Frank, M.H.; He, Y.H.; Xia, R. TBtools: An Integrative Toolkit Developed for Interactive Analyses of Big Biological Data. Mol. Plant. 2020, 13, 1194-1202. [CrossRef]

91. Du, Z.; Zhou, X.; Ling, Y.; Zhang, Z.H.; Su, Z. AgriGO: A GO Analysis Toolkit for the Agricultural Community. Nucleic Acids Res. 2010, 38, W64-W70. [CrossRef] [PubMed]

92. Kumar, S.; Stecher, G.; Tamura, K. MEGA7: Molecular Evolutionary Genetics Analysis Version 7.0 for Bigger Datasets. Mol. Biol. Evol. 2016, 33, 1870-1874. [CrossRef] [PubMed]

93. Barrett, J.C.; Fry, B.; Maller, J.; Daly, M.J. Haploview: Analysis and Visualization of LD and Haplotype Maps. Bioinformatics 2005, 21, 263-265. [CrossRef] [PubMed]

94. Reverter, A.; Fortes, M.R.S. Genome-Wide Association Studies and Genomic Prediction. Methods Mol. Biol. 2013, 1019, 321-330.

95. Endelman, J.B. Ridge Regression and Other Kernels for Genomic Selection with R Package rrBLUP. Plant. Genome 2011, 4, 250-255. [CrossRef] 